\title{
Slow-to-warm-up temperament in infancy as a predictor of concurrent and later child and maternal behaviors
}

\author{
Jessica B. Stoltzfus \\ West Virginia University
}

Follow this and additional works at: https://researchrepository.wvu.edu/etd

\section{Recommended Citation}

Stoltzfus, Jessica B., "Slow-to-warm-up temperament in infancy as a predictor of concurrent and later child and maternal behaviors" (2008). Graduate Theses, Dissertations, and Problem Reports. 4424. https://researchrepository.wvu.edu/etd/4424

This Thesis is protected by copyright and/or related rights. It has been brought to you by the The Research Repository @ WVU with permission from the rights-holder(s). You are free to use this Thesis in any way that is permitted by the copyright and related rights legislation that applies to your use. For other uses you must obtain permission from the rights-holder(s) directly, unless additional rights are indicated by a Creative Commons license in the record and/ or on the work itself. This Thesis has been accepted for inclusion in WVU Graduate Theses, Dissertations, and Problem Reports collection by an authorized administrator of The Research Repository @ WVU. For more information, please contact researchrepository@mail.wvu.edu. 
Slow-to-Warm-Up Temperament in Infancy

as a Predictor of Concurrent and Later Child and Maternal Behaviors

\author{
Jessica B. Stoltzfus
}

\begin{abstract}
THESIS
submitted to the Eberly College of Arts and Sciences

at West Virginia University

in Partial Fulfillment of the Requirements for the degree of
\end{abstract}

Master of Science

In

Psychology

Katherine Karraker, Ph.D., Chair

Tracy Morris, Ph.D.

Julie Hicks Patrick, Ph.D.

Department of Psychology

Morgantown, WV

2008

Keywords: slow-to-warm-up infant temperament, child inhibition, maternal sensitivity, parent-child relations 


\section{ABSTRACT \\ Slow-to-Warm-Up Temperament in Infancy \\ as a Predictor of Concurrent and Later Child and Maternal Behaviors}

\section{Jessica B. Stoltzfus}

Little is known about the slow-to-warm-up infant temperament. The present study evaluated the usefulness of this temperament as conceptualized by Thomas and Chess in predicting child and maternal parenting behaviors, with a particular focus on its conceptual link to child inhibition. Participants were 1,072 mothers and their children in the NICHD Study of Early Child Care. Slow-to-warm-up temperament in infancy did predict later inhibition, $p=.000$, but not as well as the difficult temperament or the individual temperament subscales of mood and approach. Including maternal sensitivity and stimulation and support increased the prediction of inhibition from the slow-to-warm-up temperament but only slightly, and only when very high or low levels of these parenting behaviors were considered. Findings suggest that the slow-towarm-up temperament may need to be redefined in order to identify children with a qualitatively different developmental trajectory from children with the difficult temperament. Future research considering the broader social context is needed to better understand the development of infants with slow-to-warm-up temperament. 


\section{ACKNOWLEDGEMENTS}

Many persons have contributed to this project. I cannot say enough to express my appreciation for the guidance, support, knowledge, and inspiration provided by my advisor and thesis chair, Dr. Katherine Karraker. I have learned so much from her during every stage of this project and am very grateful for her mentorship. I am also thankful for the comments and guidance provided by my committee members, Drs. Tracy Morris and Julie Patrick. Of course, this project would not have been possible without the many mothers and their children who participated in the NICHD Study of Early Child Care. Thank you to these participants and also to the NICHD Early Child Care Research Network for sharing the data. 


\section{TABLE OF CONTENTS}

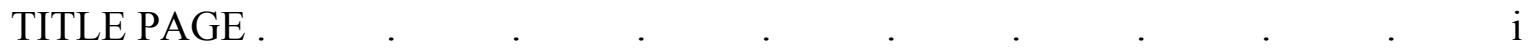

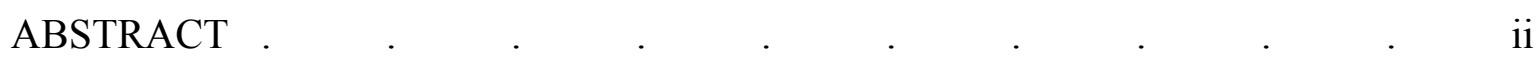

ACKNOWLEDGEMENTS . . . . . . . . . . . . . . . iii

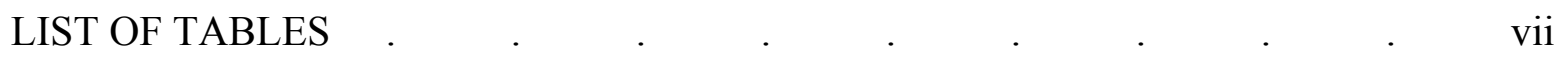

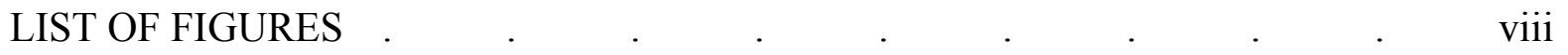

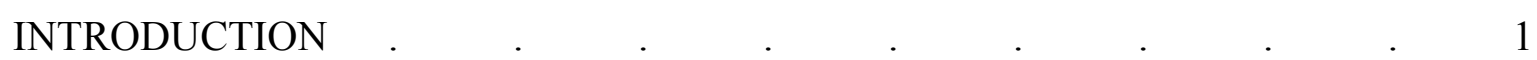

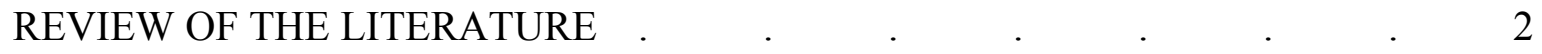

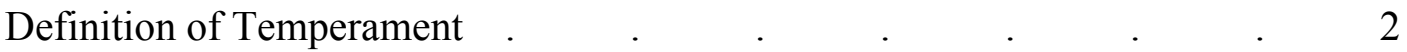

Relations between Infant Temperament and Later Inhibition $\quad . \quad$. 5

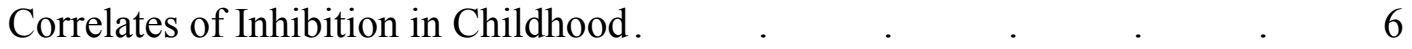

Relations between Infant Temperament and Other Child Behaviors . $\quad$. 6

Relations among Parenting, Infant Temperament, and Later Child Behaviors $\quad 8$

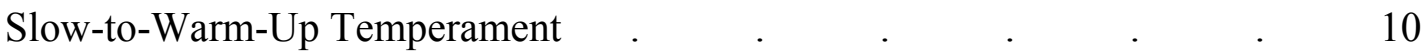

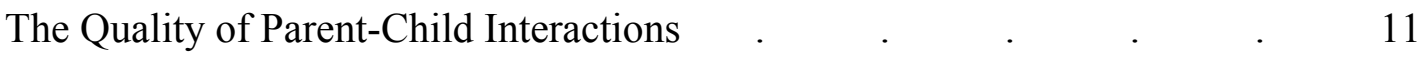

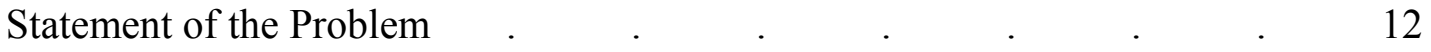

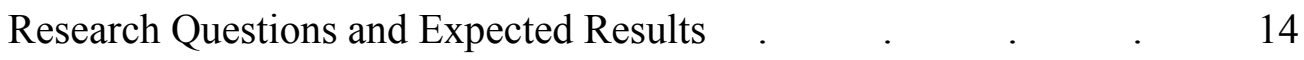

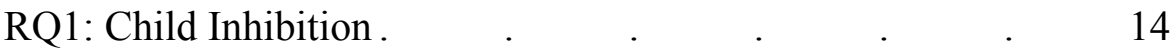

RQ2: Other Child Behaviors . $\quad . \quad$. $\quad . \quad$. 14

RQ3: Maternal Behaviors $\quad . \quad$. $\quad . \quad$. $\quad$. 15

RQ4: Maternal Behaviors and Slow-to-Warm-Up Temperament 16

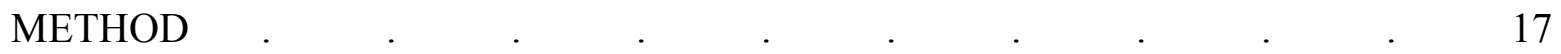

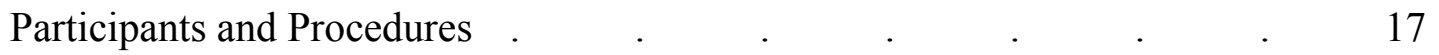




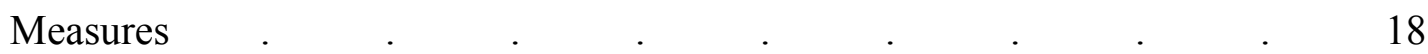

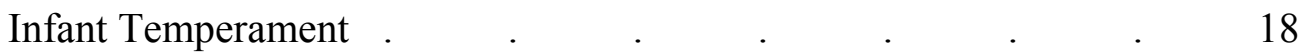

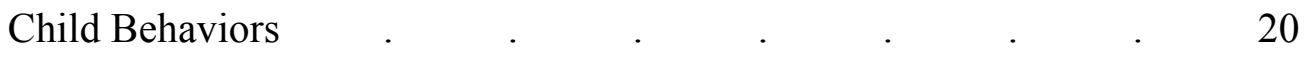

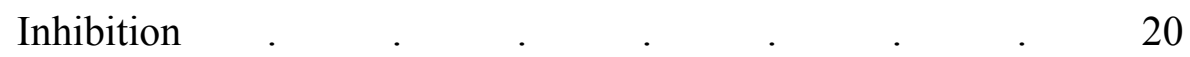

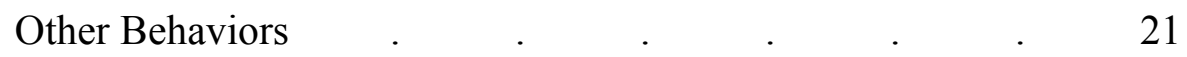

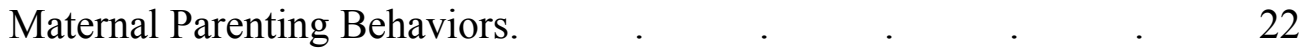

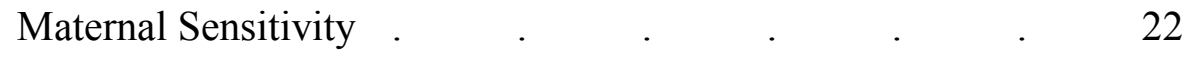

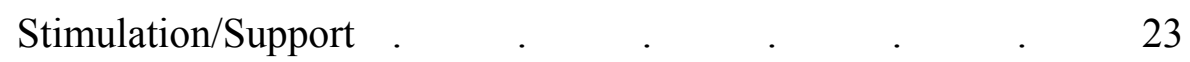

Quality of Mother-Infant Interactions. $\quad . \quad \ldots \quad$. $\quad . \quad$. $\quad 24$

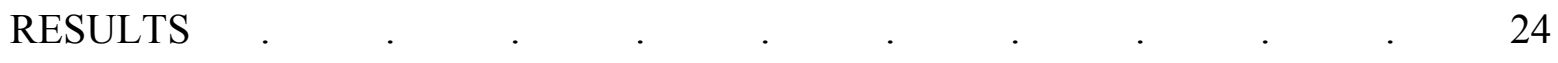

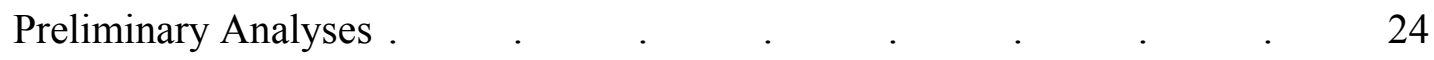

Participant Demographics $\quad . \quad$. $\quad . \quad$. $\quad . \quad$. $\quad . \quad 24$

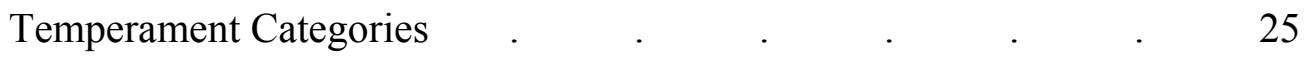

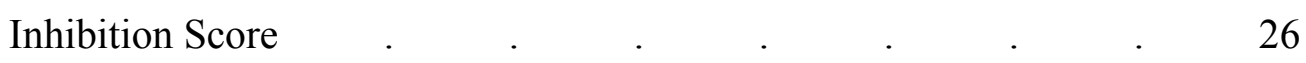

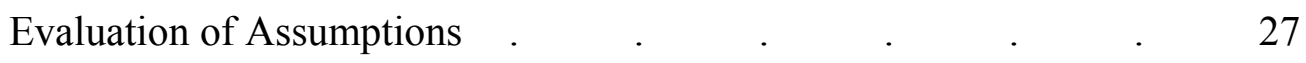

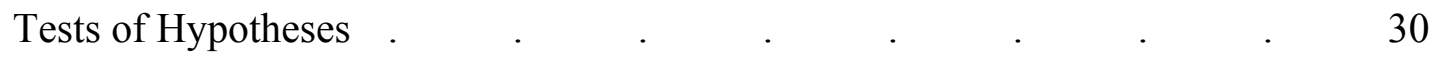

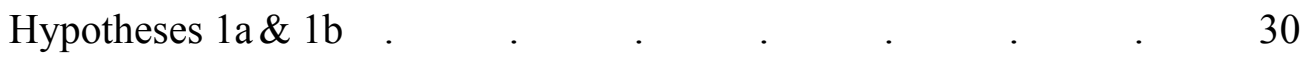

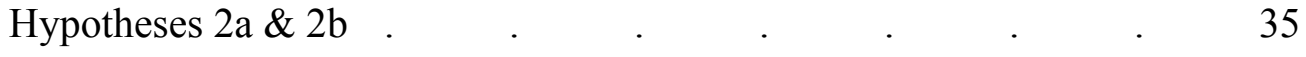

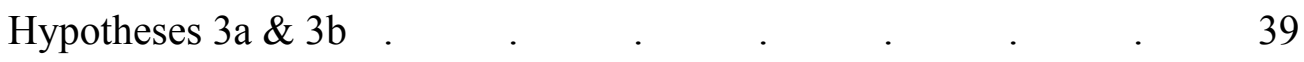

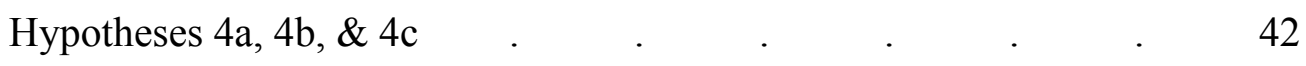

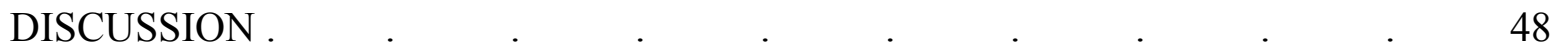

Relations between Infant Temperament and Later Inhibition $\quad$. $\quad$. $\quad 49$

Relations between Infant Temperament and Other Child Behaviors . $\quad$. $\quad 51$ 
Relations among Parenting, Infant Temperament, and Later Child Behaviors 55

Parenting the Slow-to-Warm-Up Infant $\quad$. $\quad . \quad$. 57

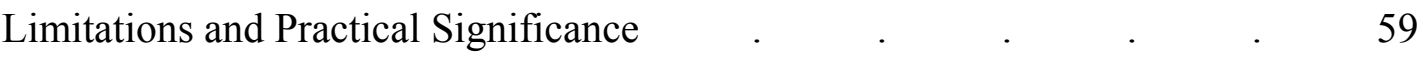

The Validity of Parent Report. $\quad$. $\quad$. $\quad$. $\quad$. $\quad$. 59

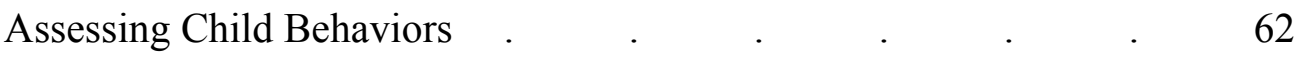

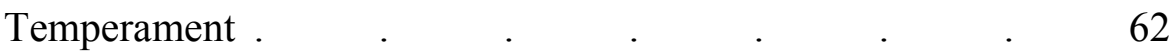

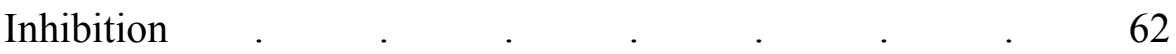

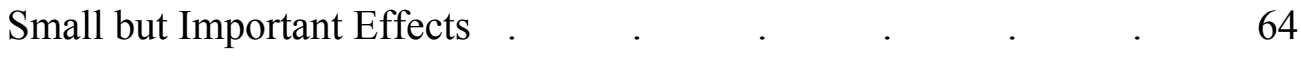

The Broader Social Context . $\quad$. $\quad . \quad$. $\quad . \quad$. 65

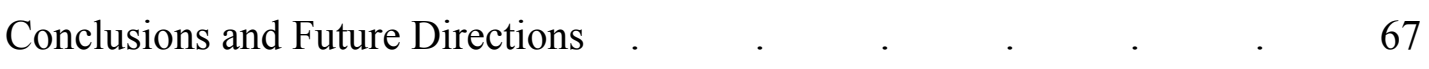

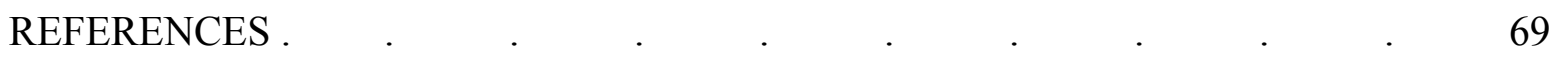




\section{LIST OF TABLES}

1. Thomas, Chess, and Birch's (1970) Dimensions and Categories of

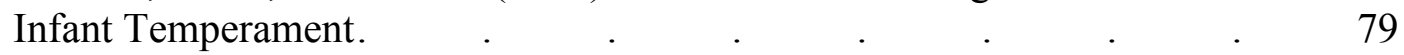

2. Reliability of Revised Infant Temperament Questionnaire Subscales

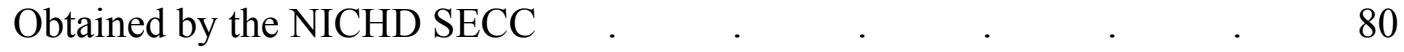

3. Means and Standard Deviations for Revised Infant Temperament Subscales Obtained by the NICHD SECC . $\quad . \quad$. $\quad . \quad$. 81

4. Reliability of Child Behavior Checklist/2-3 Subscales _ . . . $\quad 82$

5. Child Behavior Checklist/2-3 Items Relevant to Inhibition

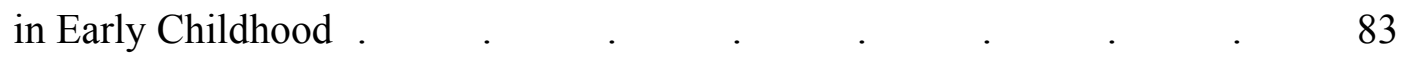

6. Stability (Test-Retest Reliability) for Maternal and Child Behaviors _ $\quad 84$

7. Mean Scores on Temperament Dimensions for Infants in Each

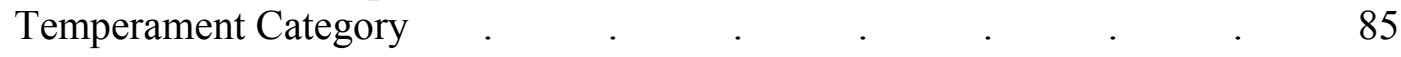

8. $\quad$ Number of Participants with Missing Data for Each Variable 86

9. Mean Scores on Dependent Variables by Temperament Category and Age in Months .

10. Summary of Regression Analyses for Variables Predicting

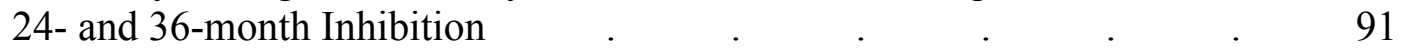

11. Analysis of Variance for Temperament and Mood at

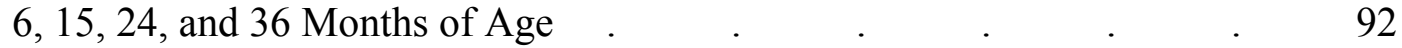

12. Mean Inhibition Score for Groups Based on Sensitivity, Stimulation/Support, and Quality of Interaction . 


\section{LIST OF FIGURES}

1. Mean inhibition by temperament at 24 and 36 months of age $\quad . \quad 94$

2. Mean activity by temperament at 6 and 24 months of age . . . . 95

3. Mean positive and negative mood rating by temperament

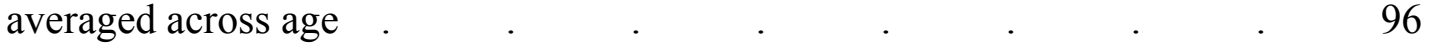

4. Mean maternal sensitivity by temperament at

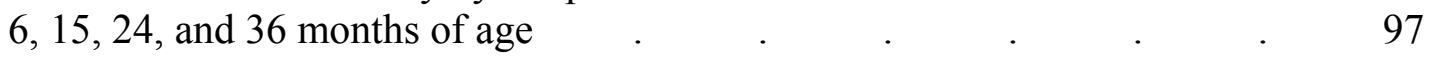

5. Mean maternal stimulation and support by temperament at

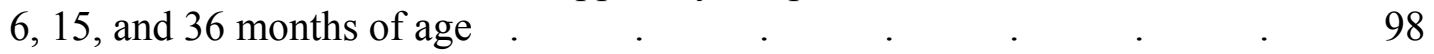

6. Mean inhibition at 24 and 36 months among children who were slow-to-warm-up in infancy by low, average, and high

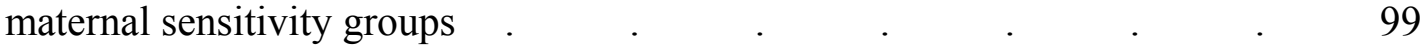

7. Mean inhibition at 24 and 36 months among children who were slow-to-warm-up in infancy by low, average, and high maternal stimulation and support groups $\quad . \quad \ldots \quad$. $\quad . \quad$. 100

8. Mean inhibition at 24 and 36 months among children who were slow-to-warm-up in infancy by average and high quality of interaction groups 


\section{Slow-to-Warm-Up Temperament in Infancy}

as a Predictor of Concurrent and Later Child and Maternal Behaviors

From birth, infants demonstrate an inherited, consistent behavioral style, or temperament, in their responses to their environment. This characteristic behavioral style is believed to influence parent-child relations and the child's social development. Much of what we know about the social and behavioral correlates of infant temperament stems from the research of Thomas and Chess and colleagues (Thomas, Chess, \& Birch, 1970; Thomas, Chess, Birch, Hertzig, \& Korn, 1963). From detailed parental descriptions of the typical behaviors of 133 infants, these researchers identified nine dimensions that describe infant behavior and derived three broad categories of infant temperament: easy, difficult, and slow-to-warm-up. The infants and their families were followed longitudinally from infancy to early adulthood (Thomas \& Chess, 1984) and beyond (Chess \& Thomas, 1990). Thomas and Chess and colleagues have reported comparisons of infants with easy and difficult temperament in terms of their behavioral outcomes in childhood (Thomas et al., 1970; Thomas, Chess, \& Korn, 1982) and adulthood (Chess \& Thomas, 1990; Thomas \& Chess, 1984).

Infants with a particular early temperament constellation may be more susceptible to certain later behaviors than infants with another constellation. Specifically, researchers have suggested infant slow-to-warm-up and difficult temperaments are risk factors for poor parentchild fit (Carey \& McDevitt, 1995) and for certain later behaviors, such as poor social competence (Houck, 1999; Houck \& LeCuyer-Maus, 2002) and inhibition (Kagan, Snidman, \& Arcus, 1998). While research indicates that infant difficult temperament and related behaviors are associated with externalizing and internalizing behaviors in toddlerhood and childhood (Bates, Maslin, \& Frankel, 1985; Sanson, Oberklaid, Pedlow, \& Prior, 1991; Warren \& Simmens, 
2005), the slow-to-warm-up category has been largely overlooked in past research. Introduction to Psychology textbooks (e.g., Bernstein, Penner, Clark-Stewart, \& Roy, 2003; Kalat, 2002) and other press (e.g., Kristal, 2007) often equate slow-to-warm-up temperament in infancy with shyness in preschool, but this link between slow-to-warm-up temperament as Thomas et al. (1970) defined the temperament and later child behaviors has yet to be empirically tested.

Research also suggests that parenting behaviors may moderate the prediction from infant temperament to later child behaviors (Belsky, Hsieh, \& Crnic, 1998; Thomas, Chess, \& Birch, 1968; as cited in Thomas et al., 1982). Moreover, infants with a constellation of behaviors that includes high negative mood or high fear are more influenced by and have more influence on parenting factors than infants with other constellations (Belsky et al., 1998; Kochanska, Aksan, \& Joy, 2007; Park, Belsky, Putnam, \& Crnic, 1997). Whereas relations among infant difficult temperament, parenting, and later child behaviors have been evaluated in past research (see reviews by Bates \& McFadyen-Ketchum, 2000 and Gallagher, 2002), similar relations with the slow-to-warm-up temperament have been largely overlooked. The general goal of the present study was to evaluate concurrent and later child and maternal behavioral correlates of infant slow-to-warm-up temperament, with a particular focus on the value of slow-to-warm-up temperament in predicting shy or inhibited behaviors in childhood.

\section{Definition of Temperament}

Temperament is generally defined as a stable, inherited pattern of behavioral responses. However, temperament is defined and studied differently by different researchers. Chess and Thomas (1999) define temperament as a construct that describes an individual's behavioral style. Specifically, "Temperament...concerns the way in which an individual behaves" (Chess \& Thomas, 1999, p. 215). Based on this view of temperament, Chess and Thomas outlined nine 
dimensions that describe infant temperament: activity level, approach/withdrawal, adaptability, mood, threshold of responsiveness, intensity, distractibility, rhythmicity, and attention span/persistence (Thomas et al., 1963). They then defined three broad categories of infant temperament: easy, difficult, and slow-to-warm-up (Thomas et al., 1970).

Thomas et al.'s (1970) dimensions and categories are outlined in Table 1. Each category is defined by a specific constellation of dimensions. The difficult infant is low in rhythmicity, approach, and adaptability, high in intensity and withdrawal, and negative in mood. About $10 \%$ of Thomas et al.'s study population was in the difficult category. The easy infant is high in rhythmicity, approach, and adaptability, mild in intensity, low in withdrawal, and positive in mood. About $40 \%$ of Thomas et al.'s sample was classified in the easy category. The slow-towarm-up infant is low in adaptability, low to moderate in activity, high in withdrawal, mild in intensity, variable in rhythmicity and distractibility, and slightly negative in mood. About $15 \%$ of Thomas et al.'s sample fell into the slow-to-warm-up category (Chess \& Thomas, 1999; Thomas et al.). The remainder of Thomas et al.'s sample did not fit into one of the three categories and was considered intermediate.

Other researchers have also contributed to our understanding of variations in temperament. Rothbart and Bates (2006) define temperament as "constitutionally based individual differences in reactivity and self-regulation, in the domains of affect, activity, and attention" (p. 100), and emphasize that the interaction between self-regulatory and reactivity components is a large determinant of the infant's temperament. Rothbart and Bates's definition of temperament expands on the categories outlined by the longitudinal research of Thomas et al. (1963) by focusing specifically on individual differences in the infant's reactivity and selfregulation of various behaviors. To these researchers, reactivity and self-regulation jointly work 
to "broadly organize the temperament domain" (Rothbart \& Bates, 2006, p. 100). This emphasis on individual differences in temperamental reactivity and self-regulation introduces the proposal that dimensions of infant temperament that influence infants' ability to regulate their reactions to their surroundings may combine to have a strong influence on infant behaviors. Similarly, Thomas and Chess and colleagues (Chess, Thomas, \& Birch, 1965; Thomas et al., 1970) also postulate that individual dimensions of temperament alone, as opposed to the overall categories, may influence the child's and the parent's later behaviors.

Kagan and Fox (2006) add to the definitions of Chess and Thomas (1999) and Rothbart and Bates (2006) to emphasize the evolving nature of temperamental influence on the developing child's behaviors. Kagan and Fox join Chess and Thomas in acknowledging the role of developmental change over time in how the child's temperament is behaviorally demonstrated, but place particular emphasis on the underlying physiological and neurological substrates of temperament that regulate such behavior change. Although temperament is biologically inherited and present from birth, these researchers have identified inherited traits that require additional brain, self-regulatory, and other developmental maturation before influencing behaviors (Kagan, 1994). Specifically, Kagan and Fox and their colleagues (Fox, Henderson, Rubin, Calkins, \& Schmidt, 2001; Kagan et al., 1998) focus on behavioral inhibition, a temperament construct that is similar to Chess and Thomas's approach-withdrawal dimension and slow-to-warm-up category. This emphasis is in line with Chess and Thomas's and Rothbart and Bates's consideration of the influence of individual dimensions of temperament, in addition to overall categories, on later child behaviors.

Although researchers study temperament differently, they generally agree that early temperament is correlated with later behavior patterns. For instance, studies have linked infant 
temperament with inhibition, a specific type of internalizing behavior, in toddlerhood and childhood.

\section{Relations between Infant Temperament and Later Inhibition}

Kagan et al. (1998) investigated infants classified as high or low in reactivity, a style of responding to novelty in infancy that was hypothesized by these researchers to be a predictor of later inhibited and uninhibited behaviors in toddlerhood and childhood. As part of a longitudinal study, 4-month-old high and low reactive infants were studied at 14 months, 21 months, and 41/2 years of age. Children classified as highly reactive in infancy demonstrated fewer comments and less positive affect (e.g., smiling) toward an unfamiliar examiner at 14 and 21 months and more inhibition in free play with peers at $4 \frac{1}{2}$ years than children classified as low in reactivity (Kagan et al.).

Park et al. (1997) also longitudinally measured the relation between temperament in infancy and later child inhibited behaviors, looking specifically at infant positive and negative emotionality as predictors of inhibition in early childhood. Positive and negative emotionality were assessed at ages 10,12 , and 13 months using questionnaires and laboratory observations. Inhibition was assessed at 36 and 37 months during laboratory observations. Children who were high in negativity and low in positivity in infancy were more inhibited than children who were low in positivity and negativity, high in positivity and negativity, or low in negativity and high in positivity in infancy (Park et al.). Park et al.'s findings demonstrate that, in addition to high reactivity to novelty (Kagan et al., 1998), high levels of negative affect in infancy are also predictive of later inhibition.

In sum, research on inhibition in toddlerhood and childhood indicates that early temperament characteristics can predict later inhibited behaviors. Infant behaviors characteristic 
of difficult and slow-to-warm-up infants (i.e., high reactivity to novelty, high negative affect) have been particularly valuable in demonstrating such links. Such studies suggest that infants with some early temperament characteristics are more susceptible to later inhibition than infants with other characteristics.

\section{Correlates of Inhibition in Childhood}

Associations between inhibited behaviors and maladaptive outcomes have been demonstrated in past research. For example, in a review of the literature on behavioral inhibition, Hirshfeld-Becker, Biederman, and Rosenbaum (2004) state that numerous studies have affirmed the hypothesized link between behavioral inhibition and later anxiety disorders. Connections have also been made between shyness, a form of inhibition that is specific to new social situations, and social withdrawal (Asendorpf, 1993). Children who withdraw from others demonstrate an increased risk for negative self-evaluations and for being negatively evaluated by their peers across childhood (Rubin, 1993). Such associations between inhibition and related constructs and later maladaptive outcomes illustrate the importance of evaluating infant temperamental precursors of child inhibition.

\section{Relations between Infant Temperament and Other Child Behaviors}

Researchers have studied relations between infant temperament and other later behaviors besides inhibition (Belsky et al., 1998; Crockenberg \& Leerkes, 2006; Houck, 1999; Warren \& Simmens, 2005). For example, Houck measured infant temperament using Thomas et al.'s (1970) categories at 8,12,24, and 36 months and child self-concept and social competence at 12, 24 , and 36 months. She found that children who were rated as temperamentally difficult in infancy and toddlerhood engaged in less adaptive social behavior than children who were not 
rated as temperamentally difficult. Specifically, high temperamental difficulty at $8,12,24$, and 36 months predicted low social competence at 24 and 36 months.

Using longitudinal data from the National Institute of Child Health and Human Development Study of Early Child Care (NICHD SECC), Warren and Simmens (2005) also evaluated infant temperament as a predictor of internalizing symptoms in toddlerhood. The study found a significant positive association between infant difficult temperament and parent- and teacher-reported depressive/anxiety symptoms at 2 and 3 years of age.

An additional study by Colder, Mott, and Berman (2002) examined the influence of particular infant temperament behaviors on later child behaviors. Similar to Kagan et al.'s (1998) investigation of infant reactivity as a precursor to later behavioral inhibition, Colder et al. focused on infant activity level and fear as temperament precursors of child internalizing and externalizing behaviors. These researchers evaluated infant fear and activity level at 1 to 11 months in relation to later externalizing and internalizing behaviors at ages 4,6 , and 8 years. They found that some aspects of infant temperament predict an escalation in internalizing and externalizing behaviors between 4 and 8 years in both boys and girls. Specifically, low fear and high activity levels in infancy predicted increases in externalizing symptoms and in depressive internalizing symptoms in boys from 4 to 8 years. Relatedly, high fear and low activity levels in infancy predicted increases in depressive internalizing symptoms from age 4 to 8 for both boys and girls.

In general, research indicates that early temperament can predict later externalizing, internalizing, and related (i.e., social competence) behavior patterns. Infant difficult temperament and other temperament behaviors (i.e., high fear, low activity level) have been particularly valuable in demonstrating such links. These findings further demonstrate the value of looking to 
infancy for temperament precursors of later maladaptive behaviors and suggest that some infants demonstrate a temperamental constellation of behaviors that makes them more vulnerable to poorer later outcomes than infants with a different constellation. This suggestion is not novel but supports similar postulations made by Chess and Thomas (1999), Kagan (1994), and others (Belsky et al., 1998).

\section{Relations among Parenting, Infant Temperament, and Later Child Behaviors}

Whereas previous studies have linked infant difficult temperament and other infant temperament behaviors to certain later child behaviors, other research examining relations among maternal interactive behavior, infant temperament, and later child behaviors illustrate the importance of considering maternal behaviors as a moderator of the relation between infant temperament and later child behaviors. A study by Crockenberg and Leerkes (2006) demonstrates that as early as 6 months of age maternal engagement and sensitivity with her infant interacts with her infant's temperament to influence the child's later behaviors. Similarly, research also suggests that parenting behaviors in toddlerhood moderate the relation between infant temperament and later behaviors. In Warren and Simmens's (2005) study investigating relations among infant temperament, gender, and toddler anxiety/depressive (internalizing) symptoms, children who were rated as temperamentally difficult in infancy and received sensitive parenting in toddlerhood demonstrated fewer anxiety/depressive symptoms than children who were rated as temperamentally difficult in infancy but did not receive sensitive parenting. This effect was stronger for boys than for girls, suggesting that temperamentally difficult boys may especially benefit from parenting practices that are high in sensitivity.

Relatedly, additional research suggests that some infants benefit more from and are more affected by particular parenting styles than other infants. In Park et al.'s (1997) study, 
associations among infant negativity, parenting strategies, and later inhibition suggest that infants with highly negative behaviors may be more likely to be affected by the quality of parenting than are infants who are not high in negativity. Specifically, they found that infants whose parents were highly sensitive were more likely than infants whose parents were low in sensitivity to be inhibited in childhood, but only if the infants were high in negativity in infancy. Further, high maternal and paternal negativity (i.e., maternal intrusiveness and paternal insensitivity and lack of protectiveness) led to less inhibition in early childhood for highly negative infants only. Park et al.'s findings support the possibility that because both slow-towarm-up and difficult infants are predominantly negative in mood, they may be more affected by particular parenting behaviors than intermediate and easy infants who characteristically demonstrate a predominantly positive mood. This proposal is consistent with a differential susceptibility model highlighted in research by Belsky (1997; Belsky et al., 1998) and others (Bakermans-Kranenburg, Van Ijzendoorn, Pijlman, Mesman, \& Juffer, 2008). Stright, Gallagher, and Kelley (2008) found support for this proposal by showing that in first grade children who were difficult in infancy demonstrated more social competence when interacting with their peers and teachers, had better quality interactions with their teachers, and were rated higher in peer status when they received high quality parenting than children who were difficult in infancy and received low quality parenting.

Researchers evaluating relations among infant temperament, maternal behaviors, and later child behaviors also acknowledge that infant temperament influences the type of parenting style the infant elicits and receives. Findings from a sample of preschoolers (Simonds \& Simonds, 1981) especially illustrate this possibility. Specifically, mothers of difficult and slowto-warm-up preschoolers were more likely to use controlling parenting styles than mothers of 
easy and intermediate preschoolers (Simonds \& Simonds). As slow-to-warm-up and difficult infants may be more affected by parenting behaviors than easy and intermediate infants, additional evaluations of how mothers parent these children in infancy, toddlerhood, and early childhood may be particularly valuable.

Relations among infant temperament, parenting, and later child behaviors have been empirically investigated. Consistent with the proposed link between certain temperament risk factors and poor outcomes (Carey \& McDevitt, 1995), findings have demonstrated the importance of considering the influence of infant temperament in combination with particular concurrent and later parenting practices on the child's later behaviors.

\section{Slow-to-Warm-Up Temperament}

In contrast to the difficult infant, little is known about what happens to the slow-to-warmup infant in toddlerhood and childhood. However, it is important to investigate the value of the slow-warm-up-temperament in predicting later child behaviors for several reasons. First, slowto-warm-up temperament is conceptually similar in makeup to difficult temperament. The slowto-warm-up infant and the difficult infant both withdraw from new situations, are slow to adapt, and are negative in mood. The established relation between difficult temperament and particular later child behaviors may also be evident with slow-to-warm-up temperament.

Second, although slow-to-warm-up and difficult infants are similar in several dimensions, the dimensions that distinguish the two groups may make the slow-to-warm-up child vulnerable to poor outcomes in different ways than the difficult child. Specifically, the two categories differ in the temperament dimensions of intensity, activity, and rhythmicity. Whereas difficult infants are high in intensity, vary in activity, and are low in rhythmicity, slow-to-warm-up infants are mild in intensity, are low to moderate in activity, and vary in rhythmicity. Slow-to-warm-up 
children may be more overlooked and less encouraged to change their initial tendency to withdraw than difficult children because their initial hesitancy to approach is paired with a mild level of intensity and a low level of activity.

Third, Carey and McDevitt (1995) propose that the slow-to-warm-up temperament is a "temperament risk factor" (p. 13) for a poor parent-child fit as well as for later problem behaviors. In their comparisons of the behavioral outcomes of children who were difficult and

easy in infancy, Thomas et al. (1970) state that their slow-to-warm-up group "accounted for...the next largest proportion" (p. 105) of behavior problems in childhood following their difficult group. However, more conclusive evidence than these findings supporting or refuting Carey and McDevitt's proposal is lacking. One goal of the present study was to evaluate relations between parent-child interactions in infancy and toddlerhood and later child behaviors for slow-to-warmup infants.

\section{The Quality of Parent-Child Interactions}

Carey and McDevitt (1995) postulate that infant difficult and slow-to-warm-up temperaments are risk factors for a poor parent-child fit. According to Chess and Thomas (1999), "poorness of fit involves discrepancies and dissonances between environmental opportunities and demands and the capacities of the organism, so that distorted development and maladaptive functioning occur" (p. 3). As a result of this dissonance, difficult and slow-to-warm-up infants may elicit and receive poorer parent behaviors than easy and intermediate infants and may therefore be less likely to experience high quality interactions with their parents than infants with a good fit. Thus, the prediction of certain later child behaviors (i.e., inhibition, high negativity) from infant slow-to-warm-up temperament may be moderated by the quality of parent-child interactions. 
Moreover, early parenting of the slow-to-warm-up infant may be especially important in the development of later adaptive or maladaptive behaviors because slow-to-warm-up infants, whose initial hesitancy to approach is paired with a mild rather than a high level of intensity, may be more likely than difficult infants to continually elicit poor parenting behaviors from their parents and other caregivers. For instance, the parent of the slow-to-warm-up infant may simply ignore the child's hesitancy to approach and low adaptability because these reactions, when paired with a low level of intensity, do not significantly affect the parent's daily functions, whereas the same characteristics, when paired with the difficult infant's high level of intensity, may severely inhibit daily functions and thus motivate the parent to try to alter such behaviors.

Overall, research indicates that infant temperament and parenting affect the likelihood that the child will experience problems in infancy, toddlerhood, early childhood, and beyond. Whereas relations among difficult temperament and other infant temperament behaviors, parenting, and later maladjustment have been studied, similar relations in infant slow-to-warmup temperament have been relatively neglected in past research. Consequently, less is known about what happens to the slow-to-warm-up infant in toddlerhood and childhood.

\section{Statement of the Problem}

Temperament describes normative individual differences and variations in inherited behaviors that combine to form an identifiable, stable constellation of traits. Children with a particular constellation of traits may be more likely to demonstrate maladaptive behaviors than children with another constellation. Specifically, difficult and slow-to-warm-up temperament patterns are suggested by some researchers (Carey \& McDevitt, 1995; Houck \& LeCuyer-Maus, 2002; Kagan et al., 1998; Warren \& Simmens, 2005) to be risk factors for poor parent-child fit and for later externalizing and internalizing behaviors. 
Associations between difficult temperament and other temperament behaviors in infancy and certain later behaviors in toddlerhood and childhood have been demonstrated in past research (Colder et al., 2002; Houck, 1999; Park et al., 1997; Warren \& Simmens, 2005). Less is known about what happens to the slow-to-warm-up infant in toddlerhood and childhood. The factors that differentiate between difficult and slow-to-warm-up infants (i.e., variable and low to moderate activity level and high and mild intensity, respectively; Thomas et al., 1970) may affect slow-to-warm-up infants' later behaviors differently than difficult infants' later behaviors. Specifically, slow-to-warm-up infants may be more overlooked and less encouraged to change their initial hesitancy to approach than difficult infants because slow-to-warm-up infants' hesitancy is paired with a mild level of intensity and a low level of activity. The slow-to-warmup temperament may be particularly valuable in predicting shy or inhibited behaviors in childhood. Although researchers have examined relations between infant difficult temperament and later inhibition, conceptually the slow-to-warm-up temperament may be more strongly linked to behavioral inhibition (Kagan, 1994; Kagan et al., 1998) and to a specific form of behavioral inhibition, shyness (Chess \& Thomas, 1986), in toddlerhood and childhood. This link has not been examined in past research.

Past research also suggests that parenting moderates relations between temperament and child adjustment, particularly in toddlerhood. Specifically, shy toddlers whose mothers are overprotective or overly forceful demonstrate more inhibition in childhood than shy toddlers whose mothers do not demonstrate such parenting styles (Kiel \& Buss, 2006; Rubin, Burgess, \& Hastings, 2002). It is possible that parenting practices associated with toddler inhibition (i.e., overprotection and forcefulness) are evident even earlier when parenting the slow-to-warm-up infant and that these practices affect later child behaviors. 
The present study evaluated the usefulness of the slow-to-warm-up temperament category in predicting concurrent and later child and maternal parenting behaviors, with a specific focus on the proposed link between infant slow-to-warm-up temperament and later inhibition. To evaluate the value of slow-to-warm-up temperament in infancy as a predictor of concurrent and later child and maternal behaviors, in the present study the following research questions and related hypotheses were addressed.

\section{Research Question 1}

What aspects of temperament during infancy best predict later inhibition?

Hypothesis 1a. Slow-to-warm-up infants will show more inhibited behavior in early childhood than will easy, intermediate, or difficult infants.

Rationale. Conceptually, the slow-to-warm-up infant temperament, categorized by low adaptability and a hesitant approach to new things, is related to the construct of inhibition (Kagan, 1994; Kagan et al., 1998).

Hypothesis $1 b$. Slow-to-warm-up infant temperament will better predict inhibited behavior in early childhood than will any single dimension of temperament (i.e., intensity, activity, approach, adaptability, and mood).

Rationale. Although past research has highlighted the predictive value of individual dimensions of temperament in addition to overall temperamental categories (e.g., Colder et al., 2002), the particular constellation of behaviors that comprise slow-to-warm-up temperament may better predict child inhibition than any single dimension.

\section{Research Question 2}

How are the concurrent and later behaviors of slow-to-warm-up infants similar to and different from the concurrent and later behaviors of easy, intermediate, and difficult infants? 
Hypothesis 2a. Slow-to-warm-up infants will demonstrate less activity than easy, intermediate, and difficult infants in infancy, toddlerhood, and early childhood.

Rationale. Slow-to-warm-up infants demonstrate low to moderate levels of activity, whereas easy, intermediate, and difficult infants vary in activity (Thomas et al., 1970). A low level of activity may persist for slow-to-warm-up infants from infancy to early childhood and affect concurrent and subsequent parent-child interactions.

Hypothesis $2 b$. Both difficult and slow-to-warm-up infants will demonstrate more negative mood than positive mood in infancy, toddlerhood, and early childhood, whereas easy and intermediate infants will demonstrate more positive mood than negative mood in infancy, toddlerhood, and early childhood.

Rationale. Both difficult and slow-to-warm-up infants are described by a predominately negative mood (Thomas et al., 1970), which may persist from infancy to early childhood and affect parent-child interactions and other later child behaviors.

\section{Research Question 3}

What concurrent and later maternal behaviors are directed toward slow-to-warm-up infants in comparison to easy, intermediate, and difficult infants?

Hypothesis 3a. Mothers of slow-to-warm-up infants will demonstrate less sensitivity toward their children in infancy, toddlerhood, and early childhood than mothers of easy, intermediate, and difficult infants.

Hypothesis $3 b$. Mothers of slow-to-warm-up infants will demonstrate less stimulation/support toward their children in infancy, toddlerhood, and early childhood than mothers of easy, intermediate, and difficult infants. 
Rationale. Mothers of slow-to-warm-up and difficult preschoolers in a previous study (Simonds \& Simonds, 1981) demonstrated more controlling (i.e., guilt inducing and distancing) behaviors than mothers of easy and intermediate preschoolers. However, the relations between temperament and maternal behaviors may be different in infancy, toddlerhood, and early childhood. In particular, mothers of slow-to-warm-up infants may be less likely than mothers of easy, intermediate, and difficult infants to notice and try to change their infants' hesitancy to approach because slow-to-warm-up infants' hesitancy to approach is paired with a low level of intensity. Mothers may overlook rather than try to control their slow-to-warm-up infants' behaviors in infancy.

\section{Research Question 4}

How does slow-to-warm-up temperament combine with maternal behaviors to predict inhibited behavior in early childhood?

Hypothesis 4a. Slow-to-warm-up infants whose mothers are average in sensitivity will be less inhibited in early childhood than slow-to-warm-up infants whose mothers are high or low in sensitivity.

Hypothesis $4 b$. Slow-to-warm-up infants whose mothers are average in stimulation/support will be less inhibited in early childhood than slow-to-warm-up infants whose mothers are high or low in stimulation/support.

Hypothesis 4c. Slow-to-warm-up infants with high quality interactions with their mothers will be less likely than slow-to-warm-up infants with low quality interactions with their mothers to demonstrate inhibited behavior in early childhood.

Rationale. The differential susceptibility model (Belsky, 1997) suggests that some infants may be more affected by characteristics of their environments (e.g., parenting) than other infants. 
Slow-to-warm-up infants may be more affected by particular parenting behaviors than difficult, intermediate, and easy infants. Relatedly, some studies have found that inhibition in toddlerhood is stable into early childhood, but only if mothers are overly controlling or overly protective toward their inhibited children (Kiel \& Buss, 2006; Rubin et al., 2002). Similar behaviors, such as low and high maternal sensitivity and stimulation/support, may be evident even earlier when parenting the slow-to-warm-up infant and lead to later inhibition.

Chess and Thomas (1999) proposed that goodness of fit between infant temperament and parenting behaviors is necessary for adaptive social and emotional development. In line with their proposal, research (Bates et al., 1985; Belsky et al., 1998; Crockenberg \& Leerkes, 2006; Sanson et al., 1991; Warren \& Simmens, 2005) has demonstrated the role of environmental factors (i.e., parenting) in the relation between infant difficult temperament and related temperament behaviors and later child problem behaviors. The quality of mother-child interactions, which in the present study was believed to be affected by goodness of fit between the infant and the mother, may be of particular importance to the slow-to-warm-up infant's adaptive emotional and behavioral development. Slow-to-warm-up infants with high quality interactions with their mothers may be less likely than slow-to-warm-up infants with low quality interactions with their mothers to demonstrate inhibition in early childhood.

Method

\section{Participants and Procedure}

Data from the National Institute of Child Health and Human Development Study of Early Child Care (NICHD SECC) were used to test the hypotheses in this study. The NICHD SECC is an ongoing longitudinal study following over 1,200 children and their families from their birth in 1991. The primary purpose of the study was to evaluate the effects of child care on the child's 
concurrent and later development and the mother-child relationship. Data were collected in phases on various child and parental characteristics and dimensions of family functioning. During Phase I, data were collected when infants were 1, 6, 15, 24, and 36 months of age. Currently, the study is in Phase IV of data collection. Additional information on participants, procedures, methods, and materials is available (NICHD Early Child Care Research Network, 2001b). For the purpose of the present study, maternal ratings of infant temperament were evaluated in relation to maternal ratings of child behavior, observational ratings of child behavior in the home and laboratory, and observational ratings of child and maternal behaviors during mother-child interactions. Data on these measures were collected from 1,364 children and their mothers. The general goal of the present study was to evaluate concurrent and later child and maternal behavioral correlates of infant slow-to-warm-up temperament.

\section{Measures}

\section{Infant Temperament}

At the 6-month interview, mothers were asked to rate their infants' behavioral characteristics with a modified version of the Revised Infant Temperament Questionnaire (My Baby - Home Version) (RITQ; Carey \& McDevitt, 1978). The RITQ is a measure by Carey and McDevitt that was derived from the longitudinal research of Thomas and Chess and colleagues (Thomas et al., 1963, 1970). The full RITQ contains 95 total items, as well as 10 items asking the mother to rate her general impressions of her infant's temperament. Each item is included in one of Thomas and Chess's nine dimensions of temperament: activity, rhythmicity, approach, adaptability, intensity, mood, persistence, distractibility, and threshold. From these subscales, the temperament categories easy, difficult, slow-to-warm-up, and intermediate are derived. The 
RITQ is administered to parents of infants between 4 and 8 months of age (BehavioralDevelopmental Initiatives, 1996).

The NICHD SECC selected 56 of the 95 original items for the 6-month RITQ (My Baby - Home Version) questionnaire. The selected items are from five of Thomas and Chess's nine dimensions of infant temperament: activity, approach, adaptability, mood, and intensity. Only five of Carey and McDevitt's (1978) nine original scales were selected by the NICHD SECC to minimize the time required for the mother to complete the questionnaire. The five items selected were considered by the NICHD SECC to provide information about the infant's temperament that is most pertinent to the infant's ability to adjust to child care and the mother-child relationship (NICHD SECC). An infant difficult temperament composite score was derived by the NICHD SECC researchers from the activity, approach, adaptability, mood, and intensity subscales, with higher scores reflecting more difficulty (i.e., lower adaptability, more intensity, and negative mood) (NICHD Early Child Care Research Network, 1999a, 2001a). Reliably for each selected subscale is provided in Table 2. Both test-retest reliability, with a mean retest interval of 25.1 days, and internal consistency are provided. Of importance, internal consistency of the subscales was low in both Carey and McDevitt's (1978) sample and the present sample. This low consistency may be due to the limited number of items that comprise each subscale or to the way in which the items were interpreted by parents that differed from how the items were intended by Carey and McDevitt.

Temperament was assessed using Thomas and Chess's dimensions only when infants were 6 months of age. For the present study, temperament scores were derived from the raw data obtained from the mothers' completion of the RITQ when the infants were 6 months of age. First, a score for each of the five subscales was calculated for each infant by finding the average rating 
of the items on each subscale (after reverse coding, as needed). Then, each infant was assigned to the difficult, slow-to-warm-up, easy, or intermediate category, based on these subscale scores. Some minor modifications in the criteria for membership in these categories (Carey \& McDevitt, 1978) were necessitated by the availability of scores for only five dimensions. The means and standard deviations from the present sample (see Table 3) were used to determine category placements.

\section{Child Behaviors}

Inhibition. At the 24- and 36-month interviews, mothers were asked to rate their children's behavioral and emotional characteristics on the Child Behavior Checklist/2-3 (CBCL/2-3; Achenbach, 1992). The CBCL/2-3 contains 99 items that are designed to assess various behavioral and emotional characteristics. The following syndrome scales were derived from the mothers' ratings: anxious/depressed, withdrawn, sleep problems, somatic problems, aggressive problems, destructive problems, internalizing total score, externalizing total score, and total problem score (NICHD SECC). Reliability for these variables is provided in Table 4. Internal consistency and test-retest reliability, with a mean retest interval of 7.7 days for Achenbach's sample and 1 year for the present sample, are provided. Test-retest reliability was lower for the present sample than for Achenbach's sample, which is likely due to the larger testretest interval for the present sample than for Achenbach's sample.

The CBCL/2-3 was selected as the measure of child inhibition for the present study because several items seem to capture behaviors typical of inhibited children in early childhood. An inhibition composite score was derived using individual items from the CBCL/2-3 that were selected because they assess behaviors highlighted in research on inhibition in toddlerhood and early childhood. Garcia Coll, Kagan, and Reznick (1984) included withdrawal behaviors, 
latencies to approach an unfamiliar person, and reluctance to leave mother as behavioral indicators of inhibition in toddlers. Putnam and Stifter (2005) identified toddlers as inhibited when they demonstrated a latency to reach for an unfamiliar toy and maintained a close proximity to their mothers during laboratory tasks. Some researchers have included anxious behaviors such as nail biting, restlessness, hair pulling, and similar behaviors, as measures of inhibition in childhood (Schmidt, Fox, Schulkin, \& Gold, 1999) and early adolescence (van Brakel, Muris, Bögels, \& Tomassen, 2006a). Other findings by van Brakel and colleagues (van Brakel, Muris, \& Derks, 2006b) suggest that children who are inhibited avoid arousal by not looking closely at aversive stimuli. Items from the CBCL/2-3 that assess these behaviors were included in the inhibition composite along with a few exploratory items (e.g., doesn't want to go out of home). Selected items are provided in Table 5. Inhibition was very stable from 24 to 36 months (see Table 6).

Other behaviors. Other child behaviors relevant to the hypotheses of the present study were measured by the NICHD SECC during observational ratings of the child during motherchild interaction procedures in the home and in the laboratory. During the 6-and 15-month home visits and the 24- and 36-month laboratory visits, child behaviors were videotaped and coded during a mother-child interaction procedure. The interaction consisted of a 15-minute free-play session. Various toys were provided. At 6, 15, and 24 months, coders rated infants' negative mood, positive mood, activity level, and sociability throughout the procedure. At 15 and 24 months, sustained attention and engagement with mother were additionally rated; sociability was not rated at 24 months. At 36 months of age, coders rated children's enthusiasm, negativity, affection toward mother, and felt security. With the exception of the measurement at 36 months, all ratings were made on a 4-point scale, from not at all characteristic to highly characteristic of 
the child. At 36 months, ratings were made on a 7-point scale, from very low to very high (NICHD SECC). The child behaviors of interest in the present study were activity, negative mood, and positive mood (see Table 6 for reliability). All child behaviors except activity from 6 to 24 months and positivity from 15 to 36 months demonstrated statistically significant stability across $6,15,24$, and 36 months of age, all $p s<.05$.

\section{Maternal Parenting Behaviors}

Past studies have found that inhibition in toddlerhood is stable into early childhood, but only if mothers are overly controlling or overly protective toward their inhibited children (Kiel \& Buss, 2006; Rubin et al., 2002). Although these parenting styles were not assessed in the NICHD SECC sample, maternal behaviors that are low or high in sensitivity and stimulation/support were considered in the present study to be similar constructs.

Maternal sensitivity. The mother-child interaction procedures were developed with the intention of eliciting and measuring the mother's typical behaviors when interacting with her child, especially her ability to sensitively and warmly stimulate her child. Maternal behaviors as well as child behaviors were coded during the procedures. During the 6, 15, and 24-month interaction procedures, the mother's sensitivity/responsivity to distress and nondistress, intrusiveness, detachment/disengagement, stimulation of development, negative regard for the child, positive regard for the child, and flatness of affect were rated. At 36 months, the mother's supportive presence, respect for child autonomy, stimulation of cognitive development, hostility, and confidence were rated. Maternal behaviors were rated on the same scale as child behaviors, from not at all characteristic to highly characteristic (NICHD SECC).

A maternal sensitivity composite score was derived by the NICHD SECC researchers from the coded variables. The score was derived at 6,15 , and 24 months from the summed 
ratings of sensitivity to nondistress, intrusiveness (reverse scored), and positive regard, and at 36 months from the summed ratings of supportive presence, hostility (reverse scored), and respect for autonomy (NICHD Early Child Care Research Network; NICHD SECC). Composite scores on these items ranged at 6,15 , and 24 months from 3 to 12 and at 36 months from 3 to 21 (NICHD Early Child Care Research Network, 1999a). The NICHD Early Child Care Research Network state that a composite score was generated and used in analyses because in past research composite scores demonstrated better validity and psychometric properties than individual scales (see Table 6 for reliability). The composite score was also used in the present study and demonstrated high stability $(p<.01)$ across all age periods.

Stimulation/support. An additional measure that is particularly useful for rating maternal behaviors in an everyday environment was used in the present study to further assess the mother's behavior with her child. The Home Observation for Measurement of the Environment (HOME) Inventory (Caldwell \& Bradley, 1984; as cited in NICHD SECC) is a 45-item measure designed to assess the amount of sensitive and stimulating support available in the home environment.

NICHD SECC observers completed the HOME Inventory Infant/Toddler version (ITHOME) during the 6- and 15-month home interviews and the HOME Inventory Early Childhood version (EC-HOME) during the 36-month home interview. Various scores related to parenting were coded by observers. Home support total, home enrichment, lack of parental negativity, parental positive involvement, and positive parenting scores were obtained at the 6-month interview. At the 15-month interview, positive parenting, lack of negativity, home support total, and home enrichment scores were obtained. The EC-HOME inventory completed at the 36month home interview rated the amount of learning materials, language stimulation, parental 
responsivity, academic stimulation, parental modeling, home variety, and parental acceptance in the home environment. A home total score was reported for each time of measurement (NICHD SECC). Test-retest reliability, provided in Table 6 , was high $(p<.01)$ across age periods. The HOME total score was used in the present study.

Quality of Mother-Infant Interactions

The NICHD SECC rating of the overall impression of the mother-child relationship was used in the present study as a measure of the quality of the mothers' interactions with their infants. Following the 6- and 15-month home interviews, an Observational Report measure was completed by the NICHD SECC observer. As part of this measure, the observer was asked to rate the mother-infant relationship as terrible, poor, fair, good, or excellent on an "overall impression of mother-infant relationship" item (NICHD SECC). This measure was considered in the present study to best capture how the mother and child match in their interactions with one another. Only the 6-month measurement was used. As the present study included only a single item coded by a single observer at one point in time, no reliability information was available.

Results

\section{Preliminary Analyses}

\section{Participant Demographics}

In the present study mothers ranged in age from 18 to 46 years, with $34.4 \%$ of the mothers between 24 and 29 years of age and another $32.7 \%$ between 30 and 35 years. Eighty-two percent of the mothers were White, $13.2 \%$ were Black, $1.8 \%$ were Asian, and $2.2 \%$ identified themselves as "Other" (2.2\%). Four percent of the mothers were Hispanic. About half (51.1\%) of the infants were male. 


\section{Temperament Categories}

Temperament data were available for 1,279 participants. As outlined by Carey (1970), only participants missing less than $20 \%$ of the items on any subscale were included in analyses, with 1,072 infants meeting this criterion. The number of participants with missing data on single items of the RITQ ranged from 323 (item 27) to 0 (items 9, 11, and 25). The number of participants with more than $20 \%$ missing data on each subscale were 2 for activity, 125 for approach, 144 for adaptability, 12 for intensity, and 3 for mood. The approach and adaptability subscales had the most participants with more than $20 \%$ of their data missing, suggesting that mothers had more difficulty rating their 6-month-old infants on these subscales than on other subscales.

The means and standard deviations for each subscale were similar to those reported by Carey and McDevitt (1995) and are reported in Table 3. Carey and McDevitt's RITQ Profile Sheet for 4- to 11-month-old infants did not provide definitions for forming the temperament categories. Instead, temperament category membership was determined using procedures outlined in the Toddler Temperament Scale Profile Sheet (Fullard, McDevitt, \& Carey, 1978). Infants above the mean on adaptability, approach, intensity, and mood, with at least two of these more than one standard deviation above the mean, were classified as difficult. Two additive criteria were used when categorizing slow-to-warm-up infants. First, infants whose activity, adaptability, approach, and mood scores were greater than the mean, and whose intensity scores were less than the mean, were placed in the slow-to-warm-up category. Second, infants who did not meet the first set of criteria but whose activity scores were no higher than one half standard deviation above the mean and mood scores were within one half standard deviation of the mean were also classified as slow-to-warm-up if they had either approach or adaptability scores greater 
than one standard deviation above the mean and intensity scores below the mean. Infants not classified as slow-to-warm-up or as difficult and with no more than two of mood, adaptability, and approach scores above the mean were classified as easy. All remaining infants were classified as intermediate. Eighty-six (8.0\%) infants were classified as difficult, $59(5.5 \%)$ as slow-to-warm-up, $492(45.9 \%)$ as easy, and $435(40.6 \%)$ as intermediate. This sample is similar in temperament category distribution to Carey and McDevitt's (1978) sample, in which 9.4\% of the infants were classified as difficult, 5.9\% as slow-to-warm-up, 42.4\% as easy, and the remaining $42.3 \%$ as intermediate. Mean scores on each temperament dimension for infants in each temperament category are reported in Table 7.

\section{Inhibition Score}

Before conducting analyses, inhibition scores were derived from mothers' responses to the CBCL/2-3. CBCL/2-3 data were available for 1,190 participants at 24 months and 1,180 participants at 36 months. As recommended by Achenbach (1992), one participant for whom data were missing for more than eight of the ninety-nine total items was deleted at both 24 and 36 months, resulting in a final sample of 1,189 participants at 24 months and 1,179 participants at 36 months. Expectation maximization (EM) via the SPSS Missing Values Analysis Program was used to impute values for those participants missing data for eight or fewer items $(N=24$ at 24 and 36 months). EM was only used for the 14 items proposed as components of inhibition (see Table 5). The program required that the CBCL/2-3 data be treated as continuous in order to compute the values. The responses on each individual item of the CBCL/2-3 range from 0 (not at all characteristic of my child) to 2 (most of the time characteristic of my child) and are thus more categorical than continuous. The use of these data as continuous is a statistical violation, but as the individual item responses were combined into a scale score the violation is minor and 
analyses of variance are robust to such violations (Howell, 2002). For none of the 14 items were $5 \%$ or more of the data missing, so these data were assumed to be missing at random and EM is an appropriate imputation technique for imputing data missing in this pattern (Tabacknick \& Fidell, 2007). Each child's scores on the fourteen individual items were summed to form his or her inhibition score. Scores ranged from 0 to 16 at 24 months and 0 to 20 at 36 months. Cronbach's alpha for inhibition was .75 at 24 months and .74 at 36 months. Although other researchers (i.e., Kagan et al., 1998, 2007) have used inhibition as a dichotomous variable with children falling in the top quarter of the sample on the inhibition measure classified as inhibited and children in the bottom quarter of the sample classified as uninhibited, in the present study the decision was made to use inhibition as a continuous variable because it fit better with these data and the properties of the scale could be retained.

\section{Evaluation of assumptions}

Preliminary tests were conducted to determine whether the data met the assumptions for each of the proposed analyses and are reported below. Participants for whom temperament data were available $(N=1,072)$ were included in analyses. Missing data for all other proposed variables (i.e., maternal sensitivity, maternal stimulation/support, inhibition, child positivity, negativity, and activity) were imputed using the EM technique provided by the SPSS Version 15.0 Missing Values Analysis Program. Consistent with a developmental approach, to prevent masking any change over time that was naturally occurring within the data, a series of EM analyses were run to impute missing data separately at each age (i.e., $6,15,24$, and 36 months). Following imputation, the data files for each age were merged into a master data file.

As recommended by the SPSS Version 15.0 Missing Values Analysis Program Users Guide, outliers were evaluated before imputation. First, outliers above the z-score absolute value 
of $3.29(p=.001)$ were identified and the value to which data needed to be recoded in order to no longer exert undue influence was determined. This approach was chosen based on the rationale that in the normal distribution, five percent of the population could be expected to exceed the absolute z-score value of 1.96, one percent could be expected to exceed the absolute z-score value of 2.58 , and no scores $(.001 \%)$ could be expected to exceed the absolute z-score value of 3.29 (Field, 2005). The value to bring outliers in to was determined by comparing the SPSS frequencies table for z-scores to the frequencies table for unstandardized scores. The unstandardized value with a z-score value of less than 3.29 replaced the outlying value. Then, after bringing in the outliers, EM was used to impute missing values. The number of data points that required imputation are reported in Table 8. Little's MCAR was nonsignificant at each age, indicating that the data were missing completely at random, $(p=.32, .68, .38$, and .59 at $6,15,24$, and 36 months, respectively). Scale scores imputed using EM were compared to scores generated using standard item mean imputation for the inhibition variable and the means and standard deviations were the same. EM was therefore considered an accurate technique for these data and was used to impute all missing data.

Outliers remaining following imputation were evaluated using z-scores as outlined by Field (2005). Values exceeding the absolute z-score values of 3.29 were brought in to a less extreme value; values were determined using the procedure outlined above. Only continuous variables were evaluated for outliers. Temperament subscale scores and the child behaviors of activity, positivity, and negativity were not evaluated for outliers, as the range of these scores was restricted. Normality was assessed using the Shapiro-Wilk test. The test was significant for all variables except for the temperament subscale activity at the $p<.01$ level, indicating a deviation from normality. As this test is affected by large samples, histograms were examined 
and for most variables the data appeared to fall under the normal curve. As an exception, negativity was substantially positively skewed at $6,15,24$, and 36 months. Log transformations were conducted to reduce skewness and kurtosis and to transform the variables to normality.

Skewness and kurtosis were assessed as outlined by Field. For skewness and kurtosis, z-scores exceeded 3.29 for all variables, which indicated significance at above the $p<.001$ level. However, as large samples yield small standard errors, it is inappropriate to use z-scores for samples above 200 (Field; Tabachnick \& Fidell, 2007). For variables that were skewed, histograms were evaluated and transformations performed if necessary. Any transformations that were performed are reported below.

Homogeneity of variance was assessed using Levene's test. Levene's test was significant at the $p<.001$ level, indicating heterogeneity in the data for the variables maternal sensitivity, maternal stimulation/support, child inhibition, child positivity, child negativity, and child activity. However, Field (2005) states that Levene's test is sensitive to the size of the sample. Small differences in group variances can yield a significant Levene's test statistic when samples are large. Thus, variance ratios were also evaluated. Using the categorical variable temperament as a factor in SPSS EXPLORE, the difference between the group with the largest variance and the group with the smallest variance was assessed for each dependent variable (i.e., maternal sensitivity, maternal stimulation/support, inhibition, child positivity, negativity, and activity). As outlined by Howell (2002), when the populations are assumed to be similar in shape (e.g., all positively skewed) and when the largest variance is no more than four times the smallest variance, heterogeneity of variance should not affect the validity of the analysis of variance and the analysis of variance can be assumed to be robust to Type I error. Variables with difference values larger than four times the smallest variance were considered to violate the assumption of 
homogeneity of variance. No variables exceeded this criterion and thus homogeneity of variance was assumed. For hypotheses tested using analysis of variance, covariance among variables (sphericity) was evaluated using Mauchly's sphericity test. Additional assumptions specific to each analysis were tested prior to conducting the proposed analyses and are reported below. An alpha level of .05 was used for all statistical tests

Cronbach's alpha was used to determine the internal reliability of the composite scores. Reliability scores for the temperament subscales activity, approach, adaptability, intensity, and mood were $.59, .57, .43, .50$, and .49 , respectively. These reliabilities are slightly lower than those attained by Carey and McDevitt (1978; see Table 2 for a comparison). For the HOME total score at 6,15 , and 36 months of age, reliabilities were $.77, .94$, and .96 , respectively. At the 6,15 , 24 , and 36-month assessments, reliability scores for maternal sensitivity were $.75, .71, .72$, and .79 , respectively. Stability over time (test-retest reliability) was assessed using Pearson product-moment correlations $(r)$ and is reported in Table 6.

\section{Tests of Hypotheses}

\section{Hypothesis $1 a$}

Slow-to-warm-up infants will show more inhibited behavior in early childhood than will easy, intermediate, or difficult infants. Assumptions specific to the analysis of variance that were not reported above were evaluated before conducting the analysis. Residual plots indicated that the assumption of linearity was met. Mauchly's sphericity test was not conducted because at least three levels of the repeated-measures variable are needed for sphericity to affect the $F$ value and in the analyses of the hypothesis only two levels of age (ages 24 months and 36 months) were tested. Box's $M$ was significant at $p=.02$, indicating that the assumption of homogeneity of variance-covariance matrices was violated. However, because this test is too strict with 
larger samples and because the analysis of variance is a robust statistical procedure (Howell, 2002), the violation was not considered to be a significant factor affecting the accuracy of the results.

A two-way mixed design analysis of variance was conducted to determine whether the slow-to-warm-up temperament category best predicted inhibition in early childhood. The between-subjects independent variable was temperament category, with four levels (easy, difficult, slow-to-warm-up, intermediate), and the within-subjects independent variable was age, with two levels (24 and 36 months). The dependent variable was inhibition. The Age $\mathrm{x}$ Temperament interaction was significant, $F(3,1068)=3.02, p=.03$, partial $\eta^{2}=.01$, the Temperament main effect was significant, $F(3,1068)=24.38, p=.000$, partial $\eta^{2}=.06$, and the Age main effect was nonsignificant, $F(1,1068)=2.17, p=.14$, partial $\eta^{2}=.00$. The Temperament main effect was qualified by the significant Age $\mathrm{x}$ Temperament interaction (see Figure 1). To isolate the effect, pairwise comparisons with the Bonferroni adjustment were conducted. Results indicated that at 24 months children who were slow-to-warm-up in infancy were significantly more inhibited than children who were easy, whereas at 36 months children who were slow-to-warm-up in infancy were significantly less inhibited than children who were difficult. Means and standard deviations are provided in Table 9.

\section{Hypothesis $1 b$}

Slow-to-warm-up infant temperament will better predict inhibited behavior in early childhood than will any single dimension of temperament (i.e., intensity, activity, approach, adaptability, and mood). Before conducting analyses, slow-to-warm-up temperament was recoded into a 2-level categorical variable. All infants who met the criteria as outlined by Carey (1970) for this temperament were considered slow-to-warm-up (coded as 1) and all others were 
designated as not slow-to-warm-up (coded as 0 ). Next, the assumptions for multiple regression were evaluated. The ratio of cases to independent variables was large, as demonstrated with the sample size exceeding the 110 participants recommended by Tabachnick and Fidell (2007) for six independent variables. This large ratio is appropriate for the present analysis as a larger cases-to-independent variables ratio is recommended when a small effect size is anticipated (Tabachnick \& Fidell). The assumption of singularity was met as indicated in collinearity diagnostics. Tolerances ranged from .47 to .85 at 24 and 36 months with none approaching zero. Collinearity diagnostics indicated that the assumption of multicollinearity was violated. One dimension had a condition index of 29.67 at both 24 and 36 months, paired with variance proportions exceeding .50 for two different variables. The multicollinearity is likely due to the fact that the slow-to-warm-up variable is comprised of a combination of the other five predictors (i.e., RITQ subscales of activity, approach, adaptability, intensity, and mood). To account for this multicollinearity, separate regressions were conducted at both ages. In one regression, slow-towarm-up temperament was entered as a predictor. Slow-to-warm-up temperament was entered as a dummy variable, with 1 indicating slow-to-warm-up temperament and 0 indicating not slow-towarm-up so that positive values would indicate that slow-to-warm-up temperament was associated with higher scores on inhibition. In another regression, the five subscales were entered as predictors. In order to determine if slow-to-warm-up temperament category membership was more predictive of inhibition than the subscales, the $R^{2}$ values of the regressions were compared using Fisher's $r$ to $z$ transformation. Also, to determine if slow-to-warm-up temperament was more predictive of inhibition than a specific subscale, the standardized regression coefficients were compared. 
With slow-to-warm-up temperament excluded, the condition index changed minimally (29.24) at 24- and 36-month inhibition, and variance proportions continued to exceed .50 for two different variables. However, although the predictors were highly correlated none exceeded .70, the rule of thumb suggested by Tabachnick and Fidell (2007) for exclusion of one of the variables, and therefore none of the variables were excluded for the reported analyses. In both the linear and multiple regression analyses, normal P-P plots of regression standardized residuals indicated a linear relation between the observed values of the dependent variable at both 24 and 36 months and the expected values, indicating that the assumptions of normality, linearity, and homoscedasticity of residuals were met. Residual statistics were evaluated for outliers. Values exceeding 20.52 were considered outliers (Tabachnick \& Fidell). For the regressions with the subscales as predictors, Mahalanobis distance ranged from .31 to 26.29 at 24 and 36 months, indicating significant outliers at $p<.001$. However, to avoid restricting the range of the dependent variable the outliers remained in the analyses. For the regressions with slow-to-warmup temperament as a predictor, Mahalanobis distance indicated there were no outliers. The assumption of independence of errors was met, as indicated by a Durbin-Watson value of 2.05 at 24 months and 2.12 at 36 months for the regressions with the subscales as predictors and 2.04 at 24 months and 2.11 at 36 months for the regressions with the temperament category as a predictor.

Linear regressions were conducted to predict 24-month inhibition and 36-month inhibition from the slow-to-warm-up temperament. Reported in Table 10 are unstandardized regression coefficients, standard error of the coefficients, standardized regression coefficients, $R^{2}$, and adjusted $R^{2}$ for the regressions predicting both 24- and 36-month inhibition. Results at 24 months indicated that the regression was significantly different from zero, $F(1,1070)=6.05, p$ 
$=.01$, with $R^{2}=.01$. However, the adjusted $R^{2}$ value of .01 indicated that very little (1\%) of the variance in inhibition was predicted from slow-to-warm-up temperament. Results at 36 months indicated that the regression was not significantly different from zero, $F(1,1070)=.17, p=.68$, with $R^{2}=.00$. The standardized regression coefficient indicated that slow-to-warm-up temperament contributed to prediction of inhibition at 24 months $(\beta=.08)$ but not at 36 months $(\beta=.01)$.

Multiple regressions with standard entry were conducted to predict 24-month inhibition and 36-month inhibition from the five subscales. Unstandardized regression coefficients, standard error of the coefficients, standardized regression coefficients, $R^{2}$, and adjusted $R^{2}$ for the regressions predicting both 24- and 36-month inhibition are reported in Table 10. Results at 24 months indicated that the regression was significantly different from zero, $F(5,1066)=21.83, p$ $=.000$, with $R^{2}=.09$. The adjusted $R^{2}$ value of .09 indicated that $9 \%$ of the variance in 24 -month inhibition was predicted by activity, approach, adaptability, mood, and intensity. Results at 36 months indicated that the regression was significantly different from zero, $F(5,1066)=15.01, p$ $=.000$, with $R^{2}=.07$. The adjusted $R^{2}$ value of .06 indicated that only $6 \%$ of the variance in inhibition was accounted for by the five predictors. Standardized regression coefficients indicated that only approach $(\beta=.19$ and .12 at 24 and 36 months, respectively) and mood ( $\beta$ $=.08$ and .10 at 24 and 36 months, respectively) contributed significantly to the prediction of inhibition at 24 and 36 months.

Comparisons of the $R^{2}$ values using Fisher's $r$ to $z$ transformation indicated that the five subscales better predicted both 24- and 36-month inhibition than the slow-to-warm-up temperament (see Table 10), $p<.001$. Moreover, comparing the two analyses, standardized regression coefficients indicated that approach, mood, and slow-to-warm-up temperament 
contributed to the prediction of inhibition at 24 months whereas only approach and mood contributed to the prediction of inhibition at 36 months (see Table 10).

Hypothesis $2 a$

Slow-to-warm-up infants will demonstrate less activity than easy, intermediate, and difficult infants in infancy, toddlerhood, and early childhood. Although it was proposed that activity would be evaluated at 6,15 , and 24 months, data on activity were available at only 6 and 24 months and only these two ages were entered as the within-subjects variable in the reported analyses. As above, assumptions specific to the analysis of variance were evaluated before conducting the analysis. Residual plots indicated that linearity was met. Mauchly's sphericity test was not conducted because at least three levels of the repeated-measures variable are needed for sphericity to affect the $F$ value and data were available at only two levels of age (ages 6 months and 24 months). Box's $M$ was nonsignificant $(p=.21)$, indicating that the assumption of homogeneity of variance-covariance matrices was met.

A two-way mixed design analysis of variance was conducted to evaluate whether children who were slow-to-warm-up in infancy demonstrated less activity at 6 and 24 months as compared to children who were easy, intermediate, and difficult. The between-subjects independent variable was temperament, with four levels (easy, difficult, slow-to-warm-up, and intermediate), and the within-subjects independent variable was age, with two levels (6 and 24 months). The dependent variable was activity. Results indicated that the Age x Temperament interaction was nonsignificant, $F(3,1068)=.57, p=.64$, partial $\eta^{2}=.00$, the Temperament main effect was nonsignificant, $F(3,1068)=2.43, p=.06$, partial $\eta^{2}=.01$, and the Age main effect was significant, $F(1,1068)=70.92, p=.000$, partial $\eta^{2}=.06$. Participants demonstrated 
significantly more activity at 24 months $(M=2.74, S D=.59)$ than at 6 months $(M=2.45, S D$ $=.56)$.

Although the Age x Temperament interaction was nonsignificant, because the a priori hypothesis predicted that children with slow-to-warm-up temperament in infancy would differ in activity from children with the other temperaments in infancy, toddlerhood, and early childhood, post hoc comparisons were conducted to determine if there were significant differences in activity among the temperament groups at 6 and 24 months. Pairwise comparisons with the Bonferroni adjustment indicated that whereas children who were slow-to-warm-up ( $M=2.29$, $S D=.46)$ in infancy demonstrated less activity at 6 months than children who were difficult ( $M$ $=2.56, S D=.56$ ), there were no significant differences among temperament groups for 24month activity. Additional means and standard deviations are reported in Table 9. To aid interpretation, the data are presented in Figure 2.

Hypothesis $2 b$

Both difficult and slow-to-warm-up infants will demonstrate more negative mood than positive mood in infancy, toddlerhood, and early childhood, whereas easy and intermediate infants will demonstrate more positive mood than negative mood in infancy, toddlerhood, and early childhood. Again, assumptions specific to the analysis of variance were first evaluated and then the analysis was conducted. Log transformations were conducted on the negativity variable at each time point to reduce skewness and kurtosis and bring the data under the normal distribution. As recommended by Tabachnick and Fidell (2007), square root and reciprocal transformations were also explored on these data but the log transformation produced skewness and kurtosis values closest to zero. Positivity was also positively skewed at 6 months for slow-towarm-up temperament and at 15 months for difficult temperament. Log transformations were 
also conducted for positivity in order to reduce this skewness. Analyses were conducted with and without negativity and positivity log transformed in order to determine whether violations of normality significantly influenced the analyses. Residual plots indicated that linearity was met. Mauchly's sphericity test was not conducted for mood because at least three levels of the repeated-measures variable are needed for sphericity to affect the $F$ value and data were available at only two levels of mood (positivity and negativity). Mauchly's test was significant at $p=.000$ for age and for mood by age, indicating that sphericity was violated in these variables. Therefore, Greenhouse-Geisser is reported in analyses because this test statistic is robust to violations of sphericity (Howell, 2002). Box's $M$ was nonsignificant $(p=.15)$, indicating that the assumption of homogeneity of variance-covariance matrices was met.

A three-way mixed design analysis of variance was conducted to evaluate whether slowto-warm-up and difficult temperament at 6 months predicted more negative than positive mood and whether intermediate and easy temperament predicted more positive than negative mood in infancy, toddlerhood, and early childhood. The between-subjects independent variable was temperament, with four levels (easy, difficult, slow-to-warm-up, and intermediate). The withinsubjects independent variables were mood, with two levels (positive and negative), and age, with four levels $(6,15,24$, and 36 months). The dependent variable was mood rating. Because of the different response range at 36 months ( 1 to 7 ) as compared to the response ranges at 6,15 , and 24 months (1 to 4), to compare across ages the data at 36 months were transformed from a 7point scale to a 4-point scale using the formula $(a+1) / 2$. Results differed in analyses with and without negativity and positivity log transformed. Therefore, reported results are based on transformed data. However, for interpretability reasons the reported means and standard deviations, provided in Table 9, are based on data without the log transformation. 
Results are reported in Table 11. In sum, the significant results were for the Mood x Temperament interaction, the Age x Mood interaction, the Mood main effect, and the Age main effect. To tease apart the significant interactions, post hoc analyses were conducted. For the Mood x Temperament interaction, visually represented in Figure 3, pairwise comparisons with the Bonferroni adjustment indicated that in each temperament group children demonstrated more positive than negative mood (see Table 9 for means and standard deviations). Pairwise comparisons also showed that children who were difficult in infancy demonstrated significantly more negative mood than children who were intermediate. The temperament groups did not differ in their level of positive mood. For the Age x Mood interaction, pairwise comparisons with the LSD adjustment showed that the participants demonstrated significantly more positive mood than negative mood at $6,15,24$, and 36 months. Additional pairwise comparisons with the Bonferroni adjustment revealed that at both 6 and 15 months participants demonstrated less positive mood than at 24 and 36 months. At 24 months, participants demonstrated more positive mood than at 6 and 15 months but less than at 36 months. At 36 months, participants demonstrated more positive mood than at any other age. For negative mood, children differed significantly in mood at only 15 months. As compared to at 15 months of age, children demonstrated more negative mood at 6, 24, and 36 months of age (see Table 9 for means and standard deviations).

Although the Age x Mood x Temperament interaction was not statically significant, because the a priori hypothesis proposed temperament differences in mood within each age, additional post hoc comparisons were conducted to explore whether differences in mood by temperament varied by age. Pairwise comparisons with the Bonferroni adjustment showed that within each temperament group children showed more positive mood than negative mood at each 
age across early childhood (see Table 9 for means and standard deviations). Additional analyses showed that children who were difficult in infancy demonstrated more negative mood than children who were easy or intermediate, but this difference was only significant at 36 months ( $M$ $=1.52, S D=.59$ for difficult and $M=1.32, S D=.48$ for intermediate). There were no additional significant differences in negative mood among the other temperament groups at any age or in the difficult temperament at 6,15 , or 24 months of age. Moreover, the temperament groups did not differ in their level of positive mood at any age.

Hypothesis $3 a$

Mothers of slow-to-warm-up infants will demonstrate less sensitivity toward their children in infancy, toddlerhood, and early childhood than mothers of easy, intermediate, and difficult infants. Before conducting analyses, assumptions specific to the analysis of variance were evaluated. Residual plots indicated that linearity was met. Box's $M$ was significant at $p$ $=.02$, indicating that the assumption of homogeneity of variance-covariance matrices was violated. However, as this test is sensitive to large samples and analyses of variance are robust to such violations (Howell, 2002), this violation was not considered to have an effect on the accuracy of the results. Sphericity was evaluated using Mauchly's test of sphericity. This test was significant at $p=.000$, indicating that sphericity was violated. To account for this violation, the Greenhouse-Geisser's statistic is reported. Finally, because response ranges differed across age (i.e., 1 to 4 at 6,15 , and 24 months; 1 to 7 at 36 months), the maternal sensitivity composite score differed in range from 3 to 12 at 6,15 , and 24 months and from 3 to 21 at 36 months. To correct for this difference the maternal sensitivity composite data at 36 months were transformed from a range of 3 to 21 to a range of 3 to 12 using the formula $(a+3) / 2$. A transformation of the 
36-month data was used rather than standardized scores in order to conduct analyses of change over time while still allowing for the possibility of detecting age changes in maternal sensitivity.

A two-way mixed design analysis of variance was conducted to evaluate associations between maternal sensitivity and the infant temperament ratings. The between-subjects independent variable was temperament, with four levels (easy, difficult, slow-to-warm-up, and intermediate), and the within-subjects independent variable was age, with four levels $(6,15,24$, and 36 months). The dependent variable was maternal sensitivity. Results indicated that the Age $\mathrm{x}$ Temperament interaction was nonsignificant, $F(8.39,2985.04)=.37, p=.94$, partial $\eta^{2}=.00$, the Temperament main effect was significant, $F(3,1068)=16.14, p=.000$, partial $\eta^{2}=.04$, and the Age main effect was significant, $F(2.80,2985.04)=49.59, p=.000$, partial $\eta^{2}=.04$. Pairwise comparisons with the Bonferroni adjustment showed that children who were slow-to-warm-up in infancy received significantly less sensitivity from their mothers than children who were easy. Moreover, on average mothers demonstrated significantly more sensitivity toward their children at 36 months than at 6,15 , or 24 months. Means and standard deviations are provided in Table 9 .

Although the Age x Temperament interaction was not statistically significant, because the a priori hypothesis proposed that mothers would differ in sensitivity by temperament category in infancy, toddlerhood, and early childhood, post hoc tests were conducted to evaluate the main effect of temperament within each age. Using the Bonferroni adjustment for multiple comparisons, post-hoc comparisons including age showed that mothers of children who were slow-to-warm-up in infancy demonstrated less sensitivity toward their children than mothers of children who were easy as infants, but this difference was only significant at 36 months (see Table 9 for means and standard deviations). Results also showed that mothers of children with 
each temperament changed in sensitivity at 36 months. To aid in interpretation, the Age $x$ Temperament interaction is visually represented in Figure 4.

Hypothesis $3 b$

Mothers of slow-to-warm-up infants will demonstrate less stimulation/support toward their children in infancy, toddlerhood, and early childhood than mothers of easy, intermediate, and difficult infants. Before conducting analyses, assumptions specific to the analysis of variance were evaluated. Residual plots showed that the assumption of linearity was met. As above, Box's $M$ was significant at $p=.000$, indicating that the assumption of homogeneity of variancecovariance matrices was violated. However, for reasons outlined above, this violation was not considered to impact the accuracy of the results. Sphericity was evaluated using Mauchly's test of sphericity. This test was significant, indicating that sphericity was violated. Therefore, the Greenhouse-Geisser's statistic is reported. Lastly, because the HOME Inventory scale differed at 36 months (55 items) as compared to 6 and 15 months (45 items), as with sensitivity, the data at 36 months were transformed from a 55 item scale to a 45 item scale using the formula [a / $(55 / 45)]$. As in the previous analysis, the transformation was conducted instead of using standardized scores through z-scores in order to detect age changes in mothers' stimulation and support.

To determine whether slow-to-warm-up infants received less stimulation and support in the everyday home environment from their mothers than easy, intermediate, and difficult infants, a two-way mixed design analysis of variance evaluated the associations between the overall HOME score and the infant temperament ratings. The between-subjects variable was temperament, with four levels (easy, difficult, slow-to-warm-up, and intermediate), and the within-subjects independent variable was age, with three levels (6, 15, and 36 months). The 
dependent variable was the overall HOME score (labeled stimulation/support). The Age $\mathrm{x}$ Temperament interaction was significant, $F(5.51,1961.95)=2.90, p=.01$, partial $\eta^{2}=.01$, the Temperament main effect was significant, $F(3,1068)=19.62, p=.000$, partial $\eta^{2}=.05$, and the Age main effect was significant, $F(1.84,1961.95)=157.00, p=.000$, partial $\eta^{2}=.13$.

To tease apart the Age x Temperament interaction, presented in Figure 5, and determine whether there were significant differences in maternal stimulation and support among the temperament groups, follow-up post hoc comparisons were conducted using the Bonferroni adjustment for multiple comparisons. Results indicated that children who were slow-to-warm-up in infancy received less stimulation and support in their home environment than children who were easy, but this difference was only significant at 15 months. Also, children who were slowto-warm-up in infancy received more stimulation and support than children who were difficult, but this difference was only significant at 36 months (see Table 9 for means and standard deviations). At 6 months, there were no significant differences in the stimulation and support demonstrated toward children who were slow-to-warm-up as compared to children who were easy, difficult, or intermediate. Also, for children who were slow-to-warm-up in infancy, mothers provided significantly less stimulation and support at 36 months as compared to the level provided at 6 and 15 months.

\section{Hypothesis $4 a$}

Slow-to-warm-up infants whose mothers are average in sensitivity will be less inhibited in early childhood than slow-to-warm-up infants whose mothers are high or low in sensitivity. To address the hypothesis, only children who were slow-to-warm-up in infancy were included. Before evaluating assumptions, to obtain the different maternal sensitivity groups the maternal sensitivity variable was split into thirds. Only the 6-month maternal sensitivity was used to 
predict inhibition. Mothers with sensitivity scores ranging from 10 to $12(N=20 ; 33.9 \%)$ were classified as high in sensitivity, mothers with scores of $9(N=23 ; 39.0 \%)$ were classified as average in sensitivity, and mothers with scores ranging from 6 to $8(N=16 ; 27.2 \%)$ were classified as low in sensitivity. Assumptions specific to the analysis of variance were then evaluated before conducting the main analysis. The assumption of linearity was assessed using residual plots and was met. Box's $M$ was nonsignificant $(p=.92)$, indicating that the assumption of homogeneity of variance-covariance matrices was met. Sphericity was not evaluated, as there were only two levels of age ( 24 and 36 months).

A two-way mixed design analysis of variance was conducted to determine whether maternal sensitivity at 6 months predicted inhibition at 24 and 36 months among children who were slow-to-warm-up in infancy. The between-subjects variable was maternal sensitivity, with three levels (low, average, high), and the within-subjects independent variable was age (24 and 36 months). The dependent variable was inhibition. Results indicated that the Age x Sensitivity interaction was nonsignificant, $F(2,56)=.19, p=.83, \eta^{2}=.01$, the Sensitivity main effect was nonsignificant, $F(2,56)=.53, p=.59, \eta^{2}=.02$, and the Age main effect was nonsignificant, $F(1$, $56)=1.22, p=.27, \eta^{2}=.02$. Although the Age $\mathrm{x}$ Sensitivity interaction and the Sensitivity main effect were nonsignificant, because the a priori hypothesis proposed that inhibition would vary by maternal sensitivity, post-hoc tests were conducted to determine whether there were significant differences in inhibition among sensitivity groups. Pairwise comparisons indicated that there were no significant differences in inhibition among the sensitivity groups at either 24 or 36 months. Means and standard deviations are reported in Table 12. To aid in interpretation, the data are presented in Figure 6. 
Although the tests of the hypothesis did not reveal significant findings, exploratory analyses were conducted to test whether results would differ when evaluating the mothers who were at the extremes of the sample in the sensitivity they demonstrated. The maternal behaviors were recoded to highlight differences between mothers who were very high and very low in sensitivity. Mothers with sensitivity scores ranging from 11 to $12(N=8 ; 13.6 \%)$ were classified as high in sensitivity, mothers with scores ranging from 8 to $10(N=41 ; 69.5 \%)$ were classified as average in sensitivity, and mothers with scores ranging from 6 to $7(N=10 ; 16.9 \%)$ were classified as low in sensitivity. The extreme sensitivity groups were tested as in the above analysis with a two-way mixed design analysis of variance. As in the previous analysis, the Age $\mathrm{x}$ Sensitivity interaction was nonsignificant, $F(2,56)=1.44, p=.25, \eta^{2}=.05$, the Sensitivity main effect was nonsignificant, $F(2,56)=2.49, p=.09, \eta^{2}=.08$, and the Age main effect was nonsignificant, $F(1,56)=3.54, p=.07, \eta^{2}=.06$. Exploratory post-hoc tests were conducted to determine whether there were significant differences in inhibition among sensitivity groups. Pairwise comparisons with the Bonferroni adjustment indicated that children who were slow-towarm-up in infancy and received a very low level of sensitivity from their mothers at 6 months $(M=9.04, S D=4.93)$ were more likely to be inhibited at 24 months than children who received an average level of sensitivity $(M=5.63, S D=3.47)$. This relation was not significant for inhibition at 36 months. Although statistically not significant, children who received a particularly high level of sensitivity tended to be inhibited at 36 months than children who received an average level of sensitivity.

Hypothesis $4 b$

Slow-to-warm-up infants whose mothers are average in stimulation/support will be less inhibited in early childhood than slow-to-warm-up infants whose mothers are high or low in 
stimulation/support. As above, to obtain the different stimulation/support groups the stimulation/support variable was split into thirds. Mothers with scores ranging from 39 to 44 ( $N$ $=21 ; 35.7 \%)$ were classified as high in stimulation/support, mothers with scores ranging from 35 to $38(N=19 ; 32.3 \%)$ were classified as average in stimulation/support, and mothers with scores ranging from 25 to $34(N=19 ; 32.2 \%)$ were classified as low in stimulation/support. Only the 6month stimulation/support measurement was used to predict later inhibition. Next, assumptions specific to the analysis were evaluated. The assumption of linearity was evaluated using residual plots and was met. Box's $M$ was nonsignificant $(p=.93)$, indicating that the assumption of homogeneity of variance-covariance matrices was met. Sphericity was not evaluated, as there were only two levels of age (24 and 36 months).

A two-way mixed design analysis of variance was conducted to determine whether high and low maternal stimulation/support at 6 months predicted inhibition at 24 and 36 months among slow-to-warm-up infants. The between-subjects independent variable was maternal stimulation/support, with three levels (low, average, high), and the within-subjects independent variable was age, with two levels (24 and 36 months). The dependent variable was inhibition. Results indicated that the Age $\mathrm{x}$ Stimulation/Support interaction was nonsignificant, $F(2,56)$ $=.54, p=.58, \eta^{2}=.02$, the Stimulation/Support main effect was nonsignificant, $F(2,56)=.64, p$ $=.53, \eta^{2}=.02$, and the Age main effect was nonsignificant, $F(1,56)=1.01, p=.32, \eta^{2}=.02$. Although the Age x Stimulation/Support interaction and the Stimulation/Support main effect were not significant, additional post hoc tests were conducted to evaluate the a priori hypothesis that children who were slow-to-warm-up in infancy and received an average level of stimulation and support would be less inhibited than children who received either a high or a low level of stimulation and support. Pairwise comparisons showed that there were no significant differences 
in inhibition among the stimulation/support groups at either 24 or 36 months. Means and standard deviations are provided in Table 12. To aid in interpretation, the data are presented in Figure 7.

Although the tests of the hypothesis did not reveal significant findings, exploratory analyses were conducted to test whether results would differ when evaluating the mothers who were very high or very low in the stimulation and support they demonstrated. Mothers with scores ranging from 41 to $44(N=12 ; 20.3 \%)$ were classified as high in stimulation/support, mothers with scores ranging from 33 to $40(N=37 ; 62.7 \%)$ were classified as average in stimulation/support, and mothers with scores ranging from 25 to $32(N=10 ; 16.9 \%)$ were classified as low in stimulation/support. Only the 6-month stimulation/support measurement was used to predict later inhibition. Extreme values of stimulation and support were tested as above using a two-way mixed analysis of variance. As above, results indicated that the Age $\mathrm{x}$ Stimulation/Support interaction was nonsignificant, $F(2,56)=1.67, p=.20, \eta^{2}=.06$, the Stimulation/Support main effect was nonsignificant, $F(2,56)=.58, p=.57, \eta^{2}=.02$, and the Age main effect was nonsignificant, $F(1,56)=2.50, p=.12, \eta^{2}=.04$. Exploratory pairwise comparisons showed that there were no significant differences in inhibition at either 24 or 36 months for children who were slow-to-warm-up in infancy and received an average level of stimulation/support as compared to children who were slow-to-warm-up in infancy and received very high or low levels of stimulation and support. Of interest, children who received very high levels of stimulation and support at 6 months demonstrated significantly less inhibition at 36 months $(M=5.50, S D=4.50)$ than at 24 months $(M=7.50, S D=4.74)$. Although not statistically different from children who received an average or a very low level of stimulation and support, at 24 months children who had received a very high level of stimulation and support 
in infancy appeared to be the most inhibited, whereas at 36 months these children appeared to be the least inhibited.

Hypothesis $4 c$

Slow-to-warm-up infants with high quality interactions with their mothers will be less likely than slow-to-warm-up infants with low quality interactions with their mothers to demonstrate inhibited behavior in early childhood. To obtain the quality of interaction groups, the quality of interaction variable was split. Interactions rated as $5(N=22 ; 37.3 \%)$ were considered high in quality, and interactions rated from 2 to $4(N=37 ; 62.7 \%)$ were considered average in quality. Although it was proposed that the quality of interaction variable would be split into high and low quality groups, only one (1.7\%) of the mother-infant interactions was rated as poor in quality and only three $(5.1 \%)$ were rated as fair in quality. The majority of the mother-child interactions were rated as either $\operatorname{good}(N=33 ; 55.9 \%)$ or excellent $(N=22 ; 37.3 \%)$ in quality. Therefore those mother-child interactions rated as excellent were considered high in quality and all other mother-infant interactions were considered average in quality. Only the 6month measurement was used to predict later inhibition. Assumptions specific to the analysis were then evaluated before conducting the analysis. Residual plots showed that linearity was met. Shapiro-Wilk test was significant at $p<.01$ for 24 - and 36-month inhibition at high quality of interaction, indicating that normality was violated at this level of quality. However, the data were not transformed and normality was assumed because analyses of variance are robust to such violations (Howell, 2002). Box's $M$ was nonsignificant $(p=.24)$, indicating that the assumption of homogeneity of variance-covariance matrices was met. As above, sphericity was not evaluated, as there were only two levels of age (24 and 36 months). 
A two-way mixed design analysis of variance was conducted to evaluate whether average quality mother-infant interactions at 6 months predicted inhibition at 24 and 36 months among slow-to-warm-up infants. The between-subjects independent variable was the quality of motherinfant interactions at 6 months, with two levels (high and average), and the within-subjects independent variable was age, with two levels (24 and 36 months). The dependent variable was inhibition. Results indicated that the Age $x$ Quality interaction was significant, $F(1,57)=6.41, p$ $=.01, \eta^{2}=.10$, the Quality main effect was nonsignificant, $F(1,57)=1.02, p=.32, \eta^{2}=.02$, and the Age main effect was nonsignificant, $F(1,57)=2.94, p=.09, \eta^{2}=.05$. Follow up analyses were conducted to tease apart the Age x Quality interaction, represented in Figure 8, and test the a priori hypothesis that children who were slow-to-warm-up in infancy and who had high quality interactions with their mothers would be less likely than children with average quality interactions to demonstrate inhibited behaviors in early childhood. Results indicated that children who had high quality interactions with their mothers in infancy became significantly less inhibited from 24 months to 36 months. Although nonsignificant, infants who had average quality interactions with their mothers tended to increase slightly in inhibition from 24 months to 36 months. Results also revealed that at neither 24 nor 36 months did children with average quality interactions with their mothers in infancy differ in inhibition from children with high quality interactions. Means and standard deviations are provided in Table 12.

\section{Discussion}

The present study investigated the usefulness of the slow-to-warm-up temperament in infancy as a predictor of concurrent and later child and maternal behaviors. The findings address whether slow-to-warm-up temperament in infancy predicts inhibition and related child behaviors in early childhood as well as whether parenting factors interact with infant temperament to 
influence later child behaviors. To summarize these findings, slow-to-warm-up temperament in infancy did predict inhibition in early childhood, but not as well as difficult infant temperament or the individual temperament subscales of mood and approach. Including parenting behaviors as moderators of the relation between slow-to-warm-up temperament and inhibition increased the predictive value of this temperament for inhibition only slightly and only when very high and very low levels of parenting were considered. Among children who were slow-to-warm-up in infancy, children who received a particularly low level of sensitivity in infancy were more inhibited as toddlers than children who received an average level of sensitivity, suggesting that early parenting behaviors do influence later behaviors in toddlerhood for slow-to-warm-up infants.

The present study also addressed the question of whether mothers of slow-to-warm-up infants behaved similarly or differently toward their children than mothers of infants with other temperaments. Compared to mothers of easy, intermediate, and difficult infants, mothers showed an "average" level of sensitivity when interacting with their children and an "average" level of stimulation and support in the everyday home environment. Children who were slow-to-warm-up in infancy received more sensitivity and more stimulation and support than children who were difficult in infancy but less than children who were easy. Overall, the findings imply that the slow-to-warm-up temperament, as conceptualized by Thomas and Chess and colleagues (Thomas et al., 1970), is less of a temperamental "risk factor" for poor later outcomes than is difficult temperament.

\section{Relations between Infant Temperament and Later Inhibition}

Despite the conceptual link between the slow-to-warm-up infant temperament, characterized by low adaptability and a hesitant approach to new things, and inhibition, past 
research has not evaluated the relation between the slow-to-warm-up infant temperament and inhibition. A primary goal of the present study was to empirically evaluate this conceptual link. The hypothesis that children who were slow-to-warm-up in infancy would be more inhibited than children with any other temperament in infancy was only minimally supported. At 24 months, children with slow-to-warm-up temperament in infancy were more inhibited than children who were easy in infancy, but they did not differ in inhibition from children who were difficult or intermediate in infancy. Moreover, these results did not extend to 36 months. At 36 months, children who were slow-to-warm-up in infancy were not more inhibited than children who were easy or intermediate in infancy and they were less inhibited than children who were difficult.

Combined, these findings suggest that children who are slow-to-warm-up in infancy tend to be inhibited in toddlerhood, but that this tendency disappears by early childhood. Rather, children who were difficult in infancy were more inhibited in early childhood than children with any other temperament. Kagan et al. (1998) showed that children who were highly reactive in infancy were inhibited in play with peers at age $4 \frac{1}{2}$ years. It is possible that intensity is associated with reactivity, with infants who are rated as high in intensity also likely to be highly reactive to Kagan et al.'s battery. Perhaps the slow-to-warm-up temperament did not predict inhibition in early childhood because this temperament is defined by a low level of intensity. As support for this proposal, in the present study the difficult temperament, which is defined by a high level of intensity, did predict inhibition in early childhood. Future research on the slow-towarm-up temperament should evaluate the potential relation between intensity and reactivity to further our understanding of the temperament's limited ability to predict child inhibition despite its conceptual link to the trait. 
Although past research has identified the value of evaluating individual temperament dimensions, or behaviors, as predictors of child inhibition, it was proposed that the particular constellation of behaviors that comprise the slow-to-warm-up temperament would better predict child inhibition than any single dimension. To address this proposal, the present study also compared the slow-to-warm-up infant temperament to the RITQ temperament subscales of intensity, activity, approach, adaptability, and mood as predictors of inhibition. Results did not support the hypothesis that slow-to-warm-up temperament in infancy would better predict inhibited behavior in early childhood than any single dimension of temperament. Instead, the mood and approach subscales more strongly predicted inhibition than did the temperament category. Thus, when evaluating relations between infant temperament and child inhibition, maternal ratings of these traits may be particularly useful in identifying children who are at risk for the poor developmental outcomes that are associated with child inhibition. In light of past research that showed that the prediction of toddler inhibition was significantly increased by combining individual traits, such as high negativity with low positivity (Park et al., 1997), the present findings suggest that future research should explore whether and how the specific infant traits of approach and mood combine to predict child inhibition. Rather than considering the slow-to-warm-up temperament category as a "temperament risk factor," the present results suggest that a better path to explore would be to identify whether there is a particular level of withdrawal that, when paired with negative mood, predicts inhibition.

\section{Relations between Infant Temperament and Other Child Behaviors}

Slow-to-warm-up infant temperament is characterized by a low level of activity, whereas easy, intermediate, and difficult infant temperaments are characterized by high or variable activity levels. It was predicted that slow-to-warm-up infants would demonstrate less activity 
than easy, intermediate, and difficult infants in infancy, toddlerhood, and early childhood. This hypothesis was partially supported, as children who were identified through mothers' ratings as slow-to-warm-up in infancy demonstrated less activity than children who were difficult.

However, this difference was only supported concurrent to the temperament assessment (i.e., at 6 months). That low activity was only concurrently related to the slow-to-warm-up temperament may indicate that activity is not stable across childhood. Rothbart and Bates (2006) acknowledge that temperament is limited in its ability to predict later adjustment because "temperament itself can change in the course of development, as a result of either experience or later-emerging traits such as attentional control" (p. 141). Other researchers also highlight that emerging properties that regulate children's behaviors can change how children's temperaments are expressed. For instance, researchers like Kagan and Fox and their colleagues (Fox et al., 2001; Kagan, 1994; Kagan et al., 1998) who study behavioral inhibition state that certain behaviors associated with this temperament do not emerge until the neurological structures that regulate these behaviors are developed. The child's activity level may vary across infancy, toddlerhood, and early childhood as the child develops the self-regulatory abilities and attentional control that modify how it is expressed.

As an alternative explanation, the inability of the present study to detect a longitudinal relation between the slow-to-warm-up temperament in infancy and activity in toddlerhood may be attributable to method variance. Method variance is defined as "method-specific distortions" (Hartmann \& Pelzel, 2005, p. 129) that alter participants' responses so that the responses do not reflect the true score but instead reflect aspects of the way the trait was measured. Stated differently by Campbell and Fiske (1959), "The systematic variance among test scores can be due to responses to the measurement features as well as responses to the trait content" (p. 81). 
Whereas temperament was assessed via parental report, activity was assessed via ratings of observed behavior. A child rated by his or her mother as low in activity may not have demonstrated the same low activity level during the observed mother-child interaction task in the laboratory at 36 months. In the present study maternal report of slow-to-warm-up temperament may have a limited ability to predict child activity because these behaviors were assessed in different modalities.

Also, the lack of stability could be due to differences in the way activity during motherchild interactions was assessed across ages. At the 24-month assessment, children's activity was coded during a structured mother-child interaction procedure that occurred in the laboratory. At the 6-month assessment, children's activity was coded in a semi-structured mother-child interaction procedure that occurred in the home. Thus, the present study was unable to determine whether the differing association between slow-to-warm-up temperament and activity at 6 months as compared to at 24 months is due to method variance or to true maturational changes in the slow-to-warm-up child. Method variance may also explain why activity demonstrated extremely low stability $(r=.04)$. At best, from the results it can be concluded that in both behavioral observations in the home and reports by the mothers, children who are slow-to-warmup do demonstrate a low level of activity as compared to children with other temperaments, particularly difficult temperament, in infancy.

It was also hypothesized that children who were slow-to-warm-up or difficult in infancy would demonstrate more negative mood than positive mood, whereas children who were easy and intermediate would demonstrate more positive mood than negative mood across early childhood. Results provided only limited support for the hypothesis. At 36 months, children who were difficult in infancy demonstrated more negative mood than children who were easy or 
intermediate. However, there were no other differences among the temperament categories in positive mood and negative mood. All of the participants demonstrated more positive mood than negative mood in infancy, toddlerhood, and early childhood. Park et al. found that children who demonstrated a high level of negativity and a low level of positivity in infancy were more likely to be inhibited in toddlerhood than children who demonstrated either a high level of both negativity and positivity, a low level of both negativity and positivity, or a low level of negativity paired with a high level of positivity. In light of Park et al.'s finding that high negative mood paired with low positive mood was related to inhibition, that slow-to-warm-up temperament in the present study was not characterized by more negative mood than positive mood could in part explain why this temperament was not a particularly strong predictor of inhibition despite its conceptual link to the trait. As compared to the other temperaments, the slow-to-warm-up temperament was not characterized by a high level of negativity paired with a particularly low level of positivity, mood characteristics that aid in the prediction of inhibition in toddlerhood.

In combination, the present findings suggest that slow-to-warm-up temperament identified in infancy may be more useful as a predictor of behaviors in or shortly after infancy, like activity in infancy or inhibition at the end of toddlerhood, rather than as a predictor of later child behaviors, like inhibition in early childhood. However, it is equally plausible that the infant temperament, assessed at 6 months, significantly predicted inhibited and other behaviors at 24months but not at 36-months because of the larger interval between the 6-month and 36-month assessments as compared to the interval between the 6-month and 24-month assessments. Researchers acknowledge that the selection of a time interval when longitudinally assessing constructs significantly affects the ability to detect existing patterns in data (Cole, 2006; Singer $\&$ Willett, 2003). Additional explorations of the relation between slow-to-warm-up temperament 
and inhibition should assess temperament and inhibition concurrently at multiple time points in toddlerhood and early childhood to better understand the relation between this temperament and early-emerging inhibited behaviors.

Slow-to-warm-up temperament could be viewed as a less extreme version of temperamental difficulty and thus may be less useful as compared to difficult temperament in predicting later poor outcomes. Much more is known about what happens to the difficult infant in childhood as compared to what the slow-to-warm-up child experiences (e.g., Houck, 1999; Warren \& Simmens, 2005). Perhaps past research has focused on the difficult infant temperament category while overlooking the slow-to-warm-up temperament because it has less extreme values on approach, mood, and other constructs with predictive value for later poor outcomes (see Table 7). In the present study the children who were slow-to-warm-up in infancy seemed to be better off in terms of inhibited and other behavioral outcomes than children who were difficult. Future research should explore additional facets of the slow-to-warm-up temperament, such as low intensity and approach, to determine whether these behaviors characteristic of the temperament have more long-term predictive value than those assessed in the present study.

\section{Relations among Parenting, Infant Temperament, and Later Child Behaviors}

It was hypothesized that children who were slow-to-warm-up in infancy would receive less sensitivity from their mothers and less stimulation and support in the everyday home environment than children who were easy, difficult, or intermediate in infancy. In large part, the hypothesis was not supported. While children who were slow-to-warm-up in infancy did receive less sensitivity from their mothers and less stimulation and support in the everyday home environment than children who were easy in infancy, it was the children who were difficult in 
infancy, as compared to children with other temperaments, who were treated differently by their mothers. According to Chess, Thomas, and Birch (1965), parents play an important role in shaping their infants' later outcomes. Parents perceive and react to their infants' temperament in ways that facilitate or hinder their children's early interactions with others in their environment.

Chess et al. state, "There is a two-way circuit between parent and child" (p. 35) to emphasize that whether or not a trait, or a particular constellation of traits, is continuous over time is a less pertinent question than how individual differences in temperament concurrently affect the child and the child's environment (i.e., parenting) at a particular stage of life (i.e., infancy). Thus, Chess and Thomas are concerned with the immediate goodness of fit between the child's temperament and characteristics of the parent.

Chess and Thomas (Chess et al., 1965) proposed that the outcomes the child experiences in childhood vary depending on whether the child experiences goodness or poorness of fit between the parent's parenting strategies and his or her temperament. For slow-to-warm-up children, mothers who attempt to force their initially hesitant child to quickly approach other children on the playground are pressuring their children to behave in a manner that is inconsistent with their temperament. Numerous unsuccessful attempts may result in the children avoiding the playground entirely, which would restrict their social interactions with new peers and their opportunity to change their hesitant, timid responses to new people and things. Similarly, slow-to-warm-up children of parents who do not push them to adapt or change at all also have poor outcomes (Chess et al.), suggesting that an average amount of encouragement and sensitivity may be best for the slow-to-warm-up child. The present study found that mothers of children who were slow-to-warm-up in infancy demonstrated less sensitivity toward their children during mother-child interactions and less stimulation and support in their everyday 
home environment than mothers of children who were easy in infancy. However, these children also received more stimulation and support than did children who were difficult in infancy. As compared to children who were easy or difficult in infancy, on average children who were slowto-warm-up in infancy elicited and received an average amount of sensitivity and an average amount of stimulation and support from their parents across early childhood. This type of parenting may represent the best fit for the slow-to-warm-up child and thus lead to positive social development, which may explain why slow-to-warm-up temperament did not emerge as a particularly strong predictor of inhibition. These children, thought to be "at risk" in infancy, may be adapting well in early childhood because of a goodness-of-fit with their mothers' parenting.

However, consistent with Thomas et al.'s (1970) statement that their slow-to-warm-up group "accounted for...the next largest proportion" (p. 105) of behavior problems in childhood following their difficult group, the slow-to-warm-up temperament was second to difficult temperament in predicting inhibition. Thus, when paired with Thomas et al.'s research the present findings suggest that Carey and McDevitt's (1995) proposal that the slow-to-warm-up temperament is a "temperament risk factor" (p. 13) for a poor parent-child fit as well as for later problem behaviors may still be applicable. The child outcomes of the slow-to-warm-up temperament in the present study merit further exploration of parenting factors that best "fit" with this temperament.

\section{Parenting the Slow-to-Warm-Up Infant}

Belsky's (1997) differential susceptibility hypothesis suggests that infants with certain temperament characteristics, such as high negativity and low approach, may be more affected by characteristics of their environments than infants without these traits. It was proposed that children who were slow-to-warm-up as infants and had mothers who demonstrated either high or 
low levels of sensitivity and stimulation and support would be more inhibited in early childhood than children who were slow-to-warm-up as infants and received "average" levels of maternal parenting. High or low sensitivity and stimulation and support were believed to be maternal behaviors emerging in infancy that are similar to overly controlling and overly protective parenting, parenting behaviors which have been previously demonstrated to lead to stability in inhibition from toddlerhood to early childhood (Kiel \& Buss, 2006; Rubin et al., 2002).

Results highlighted the importance of early parenting of the slow-to-warm-up child for his or her later toddler behaviors. When considering extreme levels of maternal parenting, among the children with slow-to-warm-up temperament as infants, children who received an average level of sensitivity in infancy were less likely than children who received a particularly low level of sensitivity to be inhibited in toddlerhood (i.e., at 24 months) but not in early childhood (i.e., at 36 months). Of interest is that children who were slow-to-warm-up in infancy and received a particularly high level of stimulation and support in infancy were more inhibited in toddlerhood than in early childhood. Although statistically these children did not differ from children who received an average or low level of stimulation and support at any age, of the children who were slow-to-warm-up in infancy they appeared to be the most inhibited in toddlerhood and the least inhibited in early childhood. This finding was surprising and suggests that there is a curvilinear relation between high stimulation and support in infancy and inhibition from toddlerhood into early childhood for the slow-to-warm-up temperament.

In Park et al.'s (1997) study, infant negativity, when paired with high levels of parental sensitivity, predicted inhibition in early childhood. The present findings suggest that Park et al.'s findings can be only minimally extended to the slow-to-warm-up child. For the slow-to-warm-up child there may be different meanings of parenting during infancy at different developmental 
stages. Early low sensitivity and high stimulation and support may at first be detrimental until the child learns to cope with the reactivity associated with his or her temperament, at which point these parenting behaviors become especially adaptive. Researchers acknowledge that there is a reciprocal relation between the parent and the child, such that characteristics of the child influence the parents' parenting behaviors and characteristics of the parent influence the behaviors the child demonstrates (Karraker \& Coleman, 2005). In the present study, mothers of children who were slow-to-warm-up in infancy did not differ in the level of sensitivity they demonstrated toward their children across infancy and toddlerhood but did increase in sensitivity in early childhood. That an increase in sensitivity was demonstrated at the same age (i.e., at 36 months) at which the slow-to-warm-up temperament was no longer a predictor of inhibition suggests that the parent is driving the change in the slow-to-warm-up infant from one age to another. Only when mothers demonstrated a low level of sensitivity toward their children who were slow-to-warm-up in infancy were these children more inhibited than children who were easy. When maternal sensitivity increased, these children were no longer more inhibited than children who were easy and were less inhibited than children who were difficult. Slow-to-warmup infants may be shaped by their parents' parenting behaviors.

\section{Limitations and Practical Significance}

\section{The Validity of Parent Report}

Temperament in the present study was assessed at one point in time (i.e., 6 months of age) using a single maternal-report measure. Chess and Thomas (1999) and colleagues considered parents to be the best reporters of their infants' temperament. Because parents have the opportunity to observe their infants in multiple settings, parents can provide useful information about their infants' behavior patterns. Thus, research on infant temperament has 
often depended on parent reports, typically using questionnaires, to measure variations in infant temperament. However, the validity of such measures is questioned by Kagan, Fox, and other temperament researchers.

Researchers who are critical of the use of parental report to assess child behaviors highlight that parents bring their own personalities and biases to their responses on parent-report temperament questionnaires. Kagan (1994) and Kagan and Fox (2006) critique the objectivity of parent questionnaires. Kagan outlines specific reasons for the limited correlation between parentreport measures and observational ratings. Parents demonstrate a tendency to dichotomize or categorize the infant into a set category, even if the infant's behaviors consistently fluctuate from one form to another (e.g., smiling and crying). Additionally, language is not broad enough to fully describe all of the qualities, including vocal, affective, and other nonverbal tendencies, that characterize the infant and the infant-parent interactions. Furthermore, parents are inconsistent in their reports, susceptible to contrast effects, varied in their perceptiveness, limited in their observatory scope (i.e., cannot rate their infant on EEG activity, vagal tone, and other physiological qualities that are not directly observable), and contradictory interpreters of the same behavior (Kagan).

Kagan (1994) states, “Parental descriptions of children's emotions and behaviors are simply not close enough to the events that the investigator wishes to know" (p. 64). However, it is possible that parental perceptions as measured in parent-report questionnaires, even though not always mirroring the child's temperament qualities as they are observed in empirical laboratory assessments, are highly consistent with parenting behaviors that then impact child adjustment. Consistent with this suggestion, Rothbart and Bates (2006) suggest that parental reports are valuable because they reveal underlying aspects of the parent-child relationship that surface only 
in parent-report measures. In support of this proposal, in the present study infant temperament, derived from maternal ratings, better predicted the level of maternal sensitivity that was demonstrated toward the child during mother-child interactions and the amount of stimulation and support that was provided in the everyday home environment than the child's positive mood, negative mood, and activity, suggesting that mothers' ratings of their children are related to the way in which they interact with their children.

Both Kagan (1994) and Rothbart and Bates (2006) acknowledge parent report and direct observations as sources of evidence. While Kagan, a strong proponent of the use of laboratory assessments when evaluating temperament, emphasizes that relying solely on parental report measures to further our understanding of temperament will yield only limited progress, Rothbart and Bates point out that observational and laboratory research techniques are flawed as well. Admittedly, the limitations of maternal report impose certain constraints on what we can gather or gain from the use of such measures. For instance, we know that parents can be influenced by the wording of questions (Mangelsdorf, Schoppe, \& Buur, 2000), that parental reports are influenced by parent characteristics like depression (NICHD Early Child Care Research Network, 1999b), and that parental reports are in part tapping into the child's behaviors but are also tapping into the parents' perceptions of their children (Seifer, 2005).

However, given these constraints, such measures can still be useful when evaluating concurrent and subsequent parenting and child behaviors. First, parents know their children across a broad array of situations and settings (Mangelsdorf et al., 2000; Seifer, 2005). Second, parents have a larger array of behaviors in mind than those that could be elicited and observed in a laboratory, and also can assess their children across extended periods of time (Mangelsdorf et al.). Such extended assessment periods are simply not possible in one or even several waves of 
data collection via laboratory observation. Third, parent reports are easy to administer and are inexpensive (Mangelsdorf et al.; Seifer). Therefore, parental report measures still deserve our attention as one way of gathering information.

\section{Assessing Child Behaviors}

Temperament. The present study conceptualized temperament using Thomas and Chess and colleagues' (Thomas et al., 1963; 1970) approach. These researchers derived their definitions of temperament from detailed parental descriptions of 133 children's behaviors. Thomas and Chess revolutionized the study of temperament. However, it is possible that their way of characterizing temperament does not get at true temperamental extremes in behaviors. As shown in Table 7, using the cutoffs suggested by Carey (1970) the slow-to-warm-up temperament was very similar to the difficult temperament. Thomas and Chess's view of the slow-to-warm-up temperament category may need to be redefined in order to identify children with a distinct, qualitatively different developmental trajectory from children with the difficult temperament.

Inhibition. In the present study, child inhibition was assessed using a linear composite of 14 selected items of the $\mathrm{CBCL} / 2-3$. Past researchers who have utilized this measure to assess inhibition in their research have used it differently than the present study. DiLalla and Caraway (2004) used the withdrawn subscale as a parental report measure for child inhibition. Petty and colleagues (2008) found that the internalizing broadband factor predicted generalized anxiety and social phobia at a 5-year follow up assessment. The present study represents a novel and pragmatic way of using the CBCL to assess inhibition. However, a limitation of the present study is that the construct inhibition was assessed only through maternal report. Inhibition is typically assessed through observational procedures because the behaviors associated with the trait (e.g., 
hesitant approach, restricted affect) are easily identifiable when triggered in a laboratory battery. Kagan et al.'s $(1998,2007)$ battery is often cited. This battery was constructed specifically to elicit child inhibition and distinguishes between children who are inhibited and children who are uninhibited across childhood (i.e., at ages 14 and 21 months and at ages 4, 7, 11, and 14 years). Children who are inhibited responded to the unfamiliar stimuli presented in this battery with higher and less variable heart rates and other physiological and behavioral indicators of inhibition. While some child researchers critique the use of parental report when assessing inhibition (e.g., Kagan, 1994), other researchers consider parent reports a valid indicator of inhibition and other child behaviors (see Rothbart \& Bates, 2006 for a review). To further our understanding of temperament and its relation with and effects on child development, researchers must utilize multiple measures (Rothbart \& Bates). In line with this recommendation, studies that paired parent reports with laboratory observations to identify children who are inhibited found that parent report measures correlate with behavioral observations (Biship, Spence, \& McDonald, 2003; DiLalla \& Caraway, 2004; Garcia Coll et al., 1984). For example, in Biship et al.'s study, fathers' reports of behavioral inhibition were significantly related to children's eye gaze and speech duration. These studies show that parental reports of inhibition do correlate with behaviors associated with the trait.

A key limitation of the present study is that the $\mathrm{CBCL}$ items selected and evaluated were identified using conceptual reasoning. The set of items identified in the present study as showing face validity with inhibition in early childhood may not be the same set of items identified by other researchers as representative of the trait. Whereas other researchers may identify additional items of pertinence to inhibition, the items included in the present study likely represent the trait as well as possible using parental report. 


\section{Small but Important Effects}

With the exception of the Mood main effect $\left(\eta^{2}=.73\right)$, significant effect sizes were small, ranging from .01 to .13. In support of the small but significant relation between infant temperament and later inhibition, Schmitz and colleagues (1999) state, "Correlations between problem behavior at age 4 and temperament during the first three years of life are moderate for children exhibiting behavior in the normal range" (p. 348). The present study's sample was not a clinically referred sample and likely demonstrated normal variations in inhibited behaviors. That significant effects for inhibition were demonstrated in the present study suggests that the demonstrated effects would be even stronger in a population that was clinically referred for inhibited behaviors.

Also in support of the importance of the small but significant demonstrated effects, previous research utilizing these data (e.g., NICHD Early Child Care Research Network, 2001a, 2003) have made the argument that these effects, though small, have a large impact on society when extended beyond the sample and multiplied by the entire population. For example, behavioral inhibition has been linked to later anxiety disorders and social withdrawal (Asendorpf, 1993; Hirshfeld-Becker et al., 2004). Identifying temperamental precursors, such as approach and mood, of inhibition holds particular value for reducing the maladaptive outcomes that are associated with inhibition. Findings generated even with small effects linking infant behaviors to child inhibition may enable researchers to identify in infancy children at risk for inhibition and also tailor interventions to the needs of children with these at-risk temperament constellations. Intervention could promote positive social development in a portion of the population and protect this at-risk subsample from experiencing the maladaptive outcomes that are associated with inhibition. 


\section{The Broader Social Context}

The present study included only mothers and their children. Future research should investigate whether similar patterns of relations are demonstrated in the father-child context and in the parent-child context. It is well known that although fathers spend less time with their infants than do mothers, from very early in their infants' lives fathers interact differently with their children than do mothers (Lamb, Bornstein, \& Teti, 2002) and play with their infants in a way that contributes uniquely to their development (Roggman, Boyce, \& Cook, 2002). For example, fathers' play behaviors are more physical and less predictable than mothers' play behaviors (Roggman et al.).

Because fathers' play is more physical and less predicable, certain temperamental behaviors like activity and intensity may be elicited and observed in interactions with fathers to a greater extent than in play with mothers. In comparison to the difficult infant, when interacting with their fathers the slow-to-warm-up infant may demonstrate low activity and low intensity. Fathers may have a unique view of these particular infant behaviors and may find these behaviors, which distinguish the slow-to-warm-up infant from the difficult infant, particularly salient because they affect their interactions with their children to a greater degree than mothers' interactions. In support of this proposal, research by Malmberg and colleagues (2007) showed that when playing with their children, fathers' but not mothers' mood changed in relation to changes in infants' mood. However, research has also shown that mothers and fathers are relatively similar in the mood and sensitivity they demonstrate toward their infants (Malmberg et al.). Such research highlights the importance of considering the broader social context in addition to the mother-child context to fully understand the constructs being examined in the present study. Future research should explore relations among father-infant interactions, infant 
temperament, and later child behaviors to determine whether these constructs relate similarly or differently for fathers' parenting in comparison to mothers' parenting.

Developmental perspectives on shyness, a form of inhibition that is specific to social situations (Asendorpf, 1993; Schmidt \& Fox, 2002) and refers to the feeling of anxiousness or fear in response to a social situation (Schmidt \& Fox), focus on the importance of social interaction and social exchange for normal development and are especially concerned with the possible consequences for children who do not interact with peers. Children who are shy experience the conflicting desire to approach or interact with others (high approach motivation) paired with a social wariness or fear to interact (high social avoidance motivation) (Rubin \& Asendorpf, 1993). It is possible that shy children who play with peers less as a result of their social fear and tendency toward withdrawal differ in their developmental outcome from children who interact frequently with peers. Piaget (1927; as cited in Rubin, 1993) proposed that children need to interact socially to develop strategies and effective ways of relating to others. Socialization with others may be particularly important for social cognition by forming an underlying base of thought processes that can be applied in later social situations (Gopnik, 1996). Consistent with these concerns, past research has outlined particular risks associated with shyness. Connections have been made between shyness and later internalizing disorders, such as depression and anxiety (Asendorpf, 1993). Connections have also been made between social withdrawal and poor interactions with peers. Children who withdraw from others are at increasing risk of negative evaluations of self and by others across childhood. Whereas in early childhood socially withdrawn children are often ignored by their peers, in middle and late childhood social withdrawal becomes increasingly associated with peer rejection (Rubin). By mid-childhood (Grade 4) social withdrawal from the peer group is seen as deviant by peers 
(Younger, Gentile, \& Burgess, 1993). In addition to peer rejection, socially withdrawn children are at increasing risk of experiencing symptoms like loneliness and negative self-evaluation (Rubin).

Combined, these findings present the possibility of a bleak outcome, where the shy child withdraws and does not develop the skills necessary to function adaptively in the social arena (Asendorpf, 1993). Children who are shy but are able to overcome their tendency to withdraw from others likely experience better outcomes than children who are shy and withdrawn.

Continued research is needed to evaluate inhibition, and specifically shyness, in relation to peer interaction and peer play and identify ways to appropriately encourage shy children to interact with unfamiliar others.

\section{Conclusion and Future Directions}

In conclusion, the present study found that the slow-to-warm-up infant temperament, as compared to the difficult temperament, does not hold particular value in predicting child inhibition or other related child behaviors, such as activity, negativity, and positivity. Moreover, evaluating maternal parenting behaviors did increase the predictive value of this temperament for child inhibition, but only when the extremes of these parenting behaviors were considered. The proposal of this temperament category as a "temperament risk factor" needs to be explored further in relation to other child behaviors and other social relations, but it seems from the present findings that these slow-to-warm-up children are better off than difficult children in early childhood. A trend of current developmental research appears to be toward delineating particular temperamentally based behaviors and specific contexts that predict later child adaptive or maladaptive outcomes, like anxiety (e.g., Buss \& Kiel, 2008). Moreover, researchers currently are moving away from Thomas and Chess's conceptualization of infant temperament in favor of 
Rothbart and colleagues' (Rothbart \& Bates, 2006; Derryberry \& Rothbart, 1988, 1997) definition and associated measures. The present study's findings do not discount the importance of evaluating a constellation of behaviors when predicting later outcomes for the slow-to-warmup infant, but rather suggest the importance of identifying a new set of constellations of behaviors through empirical research to then delineate the developmental path toward positive social outcomes for our children. 


\section{References}

Achenbach, T. M. (1992). Manual for the Child Behavior Checklist/2-3 and 1992 profile. Burlington, VT: University of Vermont Department of Psychiatry.

Asendorpf, J. B. (1993). Abnormal shyness in children. Journal of Child Psychology and Psychiatry, 34, 1069-1081.

Bakermans-Kranenburg, M. J., Van IJzendoorn, M. H., Pijlman, F. T., Mesman, J., \& Juffer, F. (2008). Experimental evidence for differential susceptibility: Dopamine D4 receptor polymorphism (DRD4 VNTR) moderates intervention effects on toddlers' externalizing behavior in a randomized controlled trial. Developmental Psychology, 44, 293-300.

Bates, J. E., Maslin, C. A., \& Frankel, K. A. (1985). Attachment security, mother-child interaction, and temperament as predictors of behavior-problem ratings at age three years. Monographs of the Society of Research in Child Development, 50(1-2).

Bates, J. E., \& McFadyen-Ketchum, S. (2000). Temperament and parent-child relations as interacting factors in children's behavioral adjustment. In V. J. Molfese \& D. L. Molfese (Eds.), Temperament and personality development across the life span (pp. 141-176). Mahwah, NJ: Lawrence Erlbaum Associates.

Behavioral-Developmental Initiatives. (1996). The Carey Temperament Scales: Professional practice set, test manual, and user's guide. Scottsdale, AZ: Behavioral-Developmental Initiatives. 
Belsky, J. (1997). Variation in susceptibility to environmental influences: An evolutionary argument. Psychological Inquiry, 8, 182-186.

Belsky, J., Hsieh, K., \& Crnic, K. (1998). Mothering, fathering, and infant negativity as antecedents of boys' externalizing problems and inhibition at age 3 years: Differential susceptibility to rearing experience? Development and Psychopathology, 10, 301-319.

Bernstein, D. A., Penner, L. A., Clarke-Stewart, A., \& Roy, E. J. (2003). Psychology (6 ${ }^{\text {th }}$ ed.). Boston: Houghton Mifflin.

Biship, G., Spence, S. H., \& McDonald, C. (2003). Can parents and teachers provide a reliable and valid report of behavioral inhibition? Child Development,74, 1899-1917.

Buss, K., \& Kiel, E. (2008, March). Factors accounting for the stability of shyness and boldness from 24 months to kindergarten. In M. Gartstein (Chair), Fear development in early childhood: Methodological considerations and factors that explain stability and growth. Symposium conducted at the biennial meeting of the International Conference on Infant Studies, Vancouver, Canada.

Campbell, D. T., \& Fiske, D. W. (1959). Convergent and discriminant validation by the multitrait-multimethod matrix. Psychological Bulletin, 56, 81-105.

Carey, W. B. (1970). A simplified method for measuring infant temperament. The Journal of Pediatrics, 77, 188-194.

Carey, W. B., \& McDevitt, S. C. (1977-1995). Revised Infant Temperament Questionnaire: Profile Sheet for 4-11-Month-Old Infants. In Behavioral-Developmental Initiatives, The Carey Temperament Scales: Professional practice set, test manual, and user's guide. Scottsdale, AZ: B-DI. 
Carey, W. B., \& McDevitt, S. C. (1978). Revision of the Infant Temperament Questionnaire. Pediatrics, 61, 735-739.

Carey, W. B., \& McDevitt, S. C. (1995). Coping with children’s temperament: A guide for professionals. New York: BasicBooks.

Chess, S., \& Thomas, A. (1986). Temperament in clinical practice. New York: The Guilford Press.

Chess, S., \& Thomas, A. (1990). The New York Longitudinal Study (NYLS): The young adult period. Canadian Journal of Psychiatry, 35, 557-561.

Chess, S., \& Thomas, A. (1999). Goodness of fit: Clinical applications from infancy through adult life. Ann Arbor, MI: Edwards Brothers.

Chess, S., Thomas, A., \& Birch, H. G. (1965). Your child is a person: A psychological approach to parenting without guilt. New York: The Viking Press.

Colder, C. R., Mott, J. A., \& Berman, A. S. (2002). The interactive effects of infant activity level and fear on growth trajectories of early childhood behavior problems. Development and Psychopathology, 14, 1-23.

Cole, D. A. (2006). Coping with longitudinal data in research on developmental psychopathology. International Journal of Behavioral Development, 30, 20-25.

Crockenberg, S. C., \& Leerkes, E. M. (2006). Infant and maternal behavior moderate reactivity to novelty to predict anxious behavior at 2.5 years. Development and Psychopathology, $18,17-34$

Derryberry, D., \& Rothbart, M. K. (1988). Arousal, affect, and attention as components of temperament. Journal of Personality and Social Psychology, 55, 958-966. 
Derryberry, D., \& Rothbart, M. K. (1997). Reactive and effortful processes in the organization of temperament. Development and Psychopathology, 9, 633-652.

DiLalla, L. F., \& Caraway, R. A. (2004). Behavioral inhibition as a function of relationship in preschool twins and siblings. Twin Research, 7, 449-455.

Field, A. (2005). Discovering statistics using SPSS ( $2^{\text {nd }}$ ed.). Thousand Oaks, CA: SAGE.

Fox, N. A., Henderson, H. A., Rubin, K. H., Calkins, S. D., \& Schmidt, L. A. (2001). Continuity and discontinuity of behavioral inhibition and exuberance: Psychophysiological and behavioral influences across the first four years of life. Child Development, 72, 1-21.

Fullard, W., McDevitt, S. C., \& Carey, W. B. (1978). Toddler Temperament Scale-Profile Sheet: Part I - for one year old children (12-23 months). Philadelphia: Temple University Press.

Gallagher, K. C. (2002). Does child temperament moderate the influence of parenting on adjustment? Developmental Review, 22, 623-643.

Garcia Coll, C., Kagan, J., \& Reznick, J. S. (1984). Behavioral inhibition in young children. Child Development, 55, 1005-1019.

Gopnik, A. (1996). The post-piaget era. Psychological Science, 7, 221-225.

Hartmann, D. P., \& Pelzel, K. E. (2005). Design, measurement, and analysis in developmental research. In M. H. Bornstein \& M. E. Lamb (Eds.), Developmental science: An advanced textbook (5 ${ }^{\text {th }}$ ed., pp. 103-186). Mahwah, NJ: Lawrence Erlbaum Associates.

Hirshfeld-Becker, D. R., Biederman, J., \& Rosenbaum, J. F. (2004). Behavioral inhibition. In T. L. Morris \& J. S. March (Eds.), Anxiety disorders in children and adolescents ( ${ }^{\text {nd }}$ ed., pp. 27-58). New York: Guilford Press. 
Houck, G. M. (1999). The measurement of child characteristics from infancy to toddlerhood: Temperament, developmental competence, self-concept, and social competence. Issues in Comprehensive Pediatric Nursing, 22, 101-127.

Houck, G. M., \& LeCuyer-Maus, E. A. (2002). Maternal limit-setting patterns and toddler development of self-concept and social competence. Issues in Comprehensive Pediatric Nursing, 25, 21-41.

Howell, D. C. (2002). Statistical methods for psychology ( $5^{\text {th }}$ ed.). Pacific Grove, CA: Wadsworth Group.

Kagan, J. (1994). Galen’s prophecy. New York: BasicBooks.

Kagan, J., \& Fox, N. A. (2006). Biology, culture, and temperamental biases. In R. M. Lerner \& W. Damon (Series Eds.) \& N. Eisenberg (Vol. Ed.), Handbook of child psychology: Vol. 3. Socialization, personality, and social development ( $6^{\text {th }}$ ed., pp. 167-225). Hoboken, NJ: John Wiley \& Sons.

Kagan, J., Snidman, N., \& Arcus, D. (1998). Childhood derivatives of high and low reactivity in infancy. Child Development, 69, 1483-1493.

Kagan, J., Snidman, N., Kahn, V., \& Towsley, S. (2007). The preservation of two infant temperaments into adolescence. Monographs of the Society for Research in Child Development, 78(2, Serial No. 287).

Kalat, J. W. (2002). Introduction to Psychology (6 ${ }^{\text {th }}$ ed.). Pacific Grove, CA: WadsworthThomson Learning.

Karraker, K. H., \& Coleman, P. K. (2005). The effects of child characteristics on parenting. In T. Luster \& L. Okagaki (Eds.), Parenting: An ecological perspective (2 ${ }^{\text {nd }}$ ed., pp. 147-176). Mahwah, NJ: Lawrence Erlbaum Associates. 
Kiel, E. J., \& Buss, K. A. (2006). Maternal accuracy in predicting toddlers' behaviors and associations with toddlers' fearful temperament. Child Development, 77, 355-370.

Kochanska, G., Aksan, N., \& Joy, M. E. (2007). Children's fearfulness as a moderator of parenting in early socialization: Two longitudinal studies. Developmental Psychology, 43, 222-237.

Kristal, J. (2007, March). Working with sensitive, withdrawing children. BehavioralDevelopmental Initiatives, 9(8). Retrieved March 21, 2007, from http://www.temperament.com/newsletter.html.

Lamb, M. E., Bornstein, M. H., \& Teti, D. M. (2002). Develoment in infancy: An introduction ( $4^{\text {th }}$ ed.). Mahwah, NJ: Lawrence Erlbaum Associates.

Malmberg, L., Stein, A., West, A., Lewis, S., Barnes, J., Leach, P., \& Sylva, K. (2007). Parentinfant interaction: A growth model approach. Infant Behavior and Development, 30, 615630.

Mangelsdorf, S. C., Schoppe, S. J., \& Buur, H. (2000). The meaning of parental reports: A contextual approach to the study of temperament and behavior problems in childhood. In V. J. Molfese \& D. L. Molfese (Eds.), Temperament and personality development across the life span (pp. 121-140). Mahwah, NJ: Lawrence Erlbaum Associates.

NICHD Early Child Care Research Network. (1999a). Child care and mother-child interaction in the first 3 years of life. Developmental Psychology, 35, 1399-1413.

NICHD Early Child Care Research Network. (1999b). Chronicity of maternal depressive symptoms, maternal sensitivity, and child functioning at 36 months. Developmental Psychology, 35, 1297-1310. 
NICHD Early Child Care Research Network. (2001a). Child care and children's peer interaction at 24 and 36 months: The NICHD Study of Early Child Care. Child Development, 72, 1478-1500.

NICHD Early Child Care Research Network. (2001b). Nonmaternal care and family factors in early development: An overview of the NICHD Study of Early Child Care. Journal of Applied Developmental Psychology, 22, 457-492.

NICHD Early Child Care Research Network. (2003). Does amount of time spent in child care predict socioemotional adjustment during the transition to kindergarten? Child Development, 74, 976-1005.

NICHD Study of Early Child Care. (n.d.). Phase I instrument document. Retrieved January 15, 2007 from http://secc.rti.org/PhaseIData.cfm

Park, S., Belsky, J., Putnam, S., \& Crnic, K. (1997). Infant emotionality, parenting, and 3-yearinhibition: Exploring stability and lawful discontinuity in a male sample. Developmental Psychology, 33, 218-227.

Petty, C. R., Rosenbaum, J. F., Hirshfeld-Becker, D. R., Henin, A., Hubley, S., LaCasse, S., Faraone, S. V., \& Biederman, J. (2008). The Child Behavior Checklist broad-band scales predict subsequent psychopathology: A 5-year follow-up. Journal of Anxiety Disorders, 22, 532-539.

Putnam, S. P., \& Stifter, C. A. (2005). Behavioral approach-inhibition in toddlers: Prediction from infancy, positive and negative affective components, and relations with behavior problems. Child Development, 76, 212-226. 
Roggman, L., Boyce, L., \& Cook, J. (2002). Widening the lens: Viewing fathers in infants' lives. In H. E. Fitzgerald, K. H. Karraker, \& T. Luster (Eds.), Infant development: Ecological perspectives. New York: RoutledgeFalmer.

Rothbart, M. K., \& Bates, J. E. (2006). Temperament. In R. M. Lerner \& W. Damon (Series Eds.) \& N. Eisenberg (Vol. Ed.), Handbook of child psychology: Vol. 3. Socialization, personality, and social development ( $6^{\text {th }}$ ed., pp. 99-166). Hoboken, NJ: John Wiley \& Sons.

Rubin, K. H. (1993). The Waterloo Longitudinal Project: Correlates and consequences of social withdrawal from childhood to adolescence. In K. H. Rubin \& J. B. Asendorpf (Eds.), Social withdrawal, inhibition, and shyness in childhood (pp. 291-314). Hillsdale, NJ: Lawrence Erlbaum Associates.

Rubin, K. H., \& Asendorpf, J. B. (1993). Social withdrawal, inhibition, and shyness in childhood: Conceptual and definitional issues. In K. H. Rubin \& J. B. Asendorpf (Eds.), Social withdrawal, inhibition, and shyness in childhood (pp. 3-17). Hillsdale, NJ: Lawrence Erlbaum Associates.

Rubin, K. H., Burgess, K. B., \& Hastings, P. D. (2002). Stability and social-behavioral consequences of toddlers' inhibited temperament and parenting behaviors. Child Development, 73, 483-495.

Sanson, A., Oberklaid, F., Pedlow, R., \& Prior, M. (1991). Risk indicators: Assessment of infancy predictors of pre-school behavioral maladjustment. Journal of Child Psychology and Psychiatry, 32, 609-626. 
Schmidt, L. A., \& Fox, N. A. (2002). Individual differences in childhood shyness: Origins, malleability, and developmental course. In D. Cervone \& W. Mischel (Eds.), Advances in personality science (pp. 83-105). New York: Guilford Press.

Schmidt, L. A., Fox, N. A., Schulkin, J., \& Gold, P. W. (1999). Behavioral and psychophysiological correlates of self-presentation in temperamentally shy children. Developmental Psychobiology, 35, 119-135.

Schmitz, S., Fulker, D. W., Plomin, R., Zahn-Waxler, C., Emde, R. N., \& DeFries, J. C. (1999). Temperament and problem behavior during early childhood. International Journal of Behavioral Development, 23, 333-355.

Seifer, R. (2005). Who should collect our data: Parents or trained observers? In D. M. Teti (Ed.), Handbook of research methods in developmental psychology (pp. 123-137). Malden, MA: Blackwell.

Simonds, M. P., \& Simonds, J. F. (1981). Relationship of maternal parenting behaviors to preschool children's temperament. Child Psychiatry and Human Development, 12, 19-31.

Singer, J. D., \& Willett, J. B. (2003). A framework for investigating change over time. In J. D. Singer \& J. B. Willett (Eds.), Applied longitudinal data analysis: Modeling change and event occurrence (pp. 3-15). Oxford: University Press.

Stright, A. D., Gallagher, K. C., \& Kelley, K. (2008). Infant temperament moderates relations between maternal parenting in early childhood and children's adjustment in first grade. Child Development, 79, 186-200.

Tabachnick, B. G., \& Fidell, L. S. (2007). Using multivariate statistics (5 ${ }^{\text {th }}$ ed.). Boston: Allyn and Bacon. 
Thomas, A., \& Chess, S. (1984). Genesis and evolution of behavioral disorders: From infancy to early adult life. The American Journal of Psychiatry, 141, 1-9.

Thomas, A., Chess, S., \& Birch, H. G. (1970). The origin of personality. Scientific American, 223, $102-107$

Thomas, A., Chess, S., Birch, H. G., Hertzig, M. E., \& Korn, S. (1963). Behavioral individuality in early childhood. New York: New York University.

Thomas, A., Chess, S., \& Korn, S. J. (1982). The reality of difficult temperament. MerrillPalmer Quarterly, 28, 1-20.

van Brakel, A. M., Muris, P., Bögels, S. M., \& Thomassen, C. (2006a). A multifactoral model for the etiology of anxiety in non-clinical adolescents: Main and interactive effects of behavioral inhibition, attachment, parental rearing. Journal of Child and Family Studies, 15, 569-579.

van Brakel, A. M., Muris, P., \& Derks, W. (2006b). Eye blink startle responses in behaviorally inhibited and uninhibited children. International Journal of Behavioral Development, 30, $460-465$.

Warren, S. L., \& Simmens, S. J. (2005). Predicting toddler anxiety/depressive symptoms: Effects of caregiver sensitivity on temperamentally vulnerable children. Infant Mental Health Journal, 26, 40-55.

Younger, A., Gentile, C., \& Burgess, K. (1993). Children's perceptions of social withdrawal: Changes across age. In K. H. Rubin \& J. B. Asendorpf (Eds.), Social withdrawal, inhibition, and shyness in childhood (pp. 215-235). Hillsdale, NJ: Lawrence Erlbaum Associates. 
Table 1

Thomas, Chess, and Birch's (1970) Dimensions and Categories of Infant Temperament

\begin{tabular}{|c|c|c|c|c|c|c|c|c|c|}
\hline $\begin{array}{l}\text { Type of } \\
\text { child }\end{array}$ & $\begin{array}{l}\text { Activity } \\
\text { level }\end{array}$ & Rhythmicity & $\begin{array}{l}\text { Distractibil- } \\
\text { ity }\end{array}$ & $\begin{array}{c}\text { Approach } \\
\text { withdrawal }\end{array}$ & Adaptability & $\begin{array}{l}\text { Attention } \\
\text { span and } \\
\text { persistence }\end{array}$ & $\begin{array}{l}\text { Intensity } \\
\text { of reaction }\end{array}$ & $\begin{array}{l}\text { Threshold } \\
\text { of } \\
\text { responsive- } \\
\text { ness }\end{array}$ & $\begin{array}{l}\text { Quality of } \\
\text { mood }\end{array}$ \\
\hline & $\begin{array}{l}\text { The } \\
\text { proportion } \\
\text { of active } \\
\text { periods to } \\
\text { inactive } \\
\text { ones }\end{array}$ & $\begin{array}{l}\text { Regularity of } \\
\text { hunger, } \\
\text { excretion, } \\
\text { sleep and } \\
\text { wakefulness }\end{array}$ & $\begin{array}{l}\text { The degree } \\
\text { to which } \\
\text { extraneous } \\
\text { stimuli alter } \\
\text { behavior }\end{array}$ & $\begin{array}{l}\text { The } \\
\text { response to } \\
\text { a new } \\
\text { object or } \\
\text { person }\end{array}$ & $\begin{array}{l}\text { The ease } \\
\text { with which a } \\
\text { child adapts } \\
\text { to changes in } \\
\text { environment }\end{array}$ & $\begin{array}{l}\text { The amount } \\
\text { of time } \\
\text { devoted to } \\
\text { an activity, } \\
\text { and the } \\
\text { effect of } \\
\text { distraction } \\
\text { on the } \\
\text { activity }\end{array}$ & $\begin{array}{l}\text { The } \\
\text { energy of } \\
\text { response, } \\
\text { regardless } \\
\text { of its } \\
\text { quality or } \\
\text { direction }\end{array}$ & $\begin{array}{l}\text { The } \\
\text { intensity of } \\
\text { stimulation } \\
\text { required to } \\
\text { evoke a } \\
\text { discernible } \\
\text { response }\end{array}$ & $\begin{array}{l}\text { The amount } \\
\text { of friendly, } \\
\text { pleasant, } \\
\text { joyful } \\
\text { behavior as } \\
\text { contrasted } \\
\text { with } \\
\text { unpleasant, } \\
\text { unfriendly } \\
\text { behavior }\end{array}$ \\
\hline "Easy" & Varies & Very regular & Varies & $\begin{array}{l}\text { Positive } \\
\text { approach }\end{array}$ & $\begin{array}{c}\text { Very } \\
\text { adaptable }\end{array}$ & High or low & $\begin{array}{l}\text { Low or } \\
\text { mild }\end{array}$ & High or low & Positive \\
\hline $\begin{array}{l}\text { "Slow to } \\
\text { warm up" }\end{array}$ & $\begin{array}{l}\text { Low to } \\
\text { moderate }\end{array}$ & Varies & Varies & $\begin{array}{c}\text { Initial } \\
\text { withdrawal }\end{array}$ & $\begin{array}{c}\text { Slowly } \\
\text { adaptable }\end{array}$ & High or low & Mild & High or low & $\begin{array}{l}\text { Slightly } \\
\text { negative }\end{array}$ \\
\hline "Difficult" & Varies & Irregular & Varies & Withdrawal & $\begin{array}{c}\text { Slowly } \\
\text { adaptable }\end{array}$ & High or low & Intense & High or low & Negative \\
\hline
\end{tabular}

Note. From “The Origin of Personality,” by A. Thomas, S. Chess, \& H. G. Birch, 1970, Scientific American, 223, p. $106-107$. 
Table 2

Reliability of Revised Infant Temperament Questionnaire Subscales Obtained by the NICHD SECC

\begin{tabular}{|c|c|c|c|c|c|}
\hline \multirow[b]{2}{*}{ Measure } & \multirow[b]{2}{*}{ Subscale } & \multicolumn{2}{|c|}{ Test-retest reliability } & \multicolumn{2}{|c|}{ Internal consistency } \\
\hline & & $\begin{array}{c}\text { Carey and } \\
\text { McDevitt's } \\
\text { sample }^{\mathrm{a}} \\
\end{array}$ & $\begin{array}{c}\text { NICHD } \\
\text { SECC } \\
\text { sample } \\
\end{array}$ & $\begin{array}{c}\text { Carey and } \\
\text { McDevitt's } \\
\text { sample }^{b}\end{array}$ & $\begin{array}{c}\text { NICHD } \\
\text { SECC } \\
\text { sample }\end{array}$ \\
\hline \multirow[t]{5}{*}{ RITQ } & Activity & .78 & & .64 & .59 \\
\hline & Approach & .77 & & .71 & .57 \\
\hline & Adaptability & .74 & & .57 & .43 \\
\hline & Intensity & .66 & & .56 & .50 \\
\hline & Mood & .81 & & .53 & .49 \\
\hline$N$ & & 41 & & 203 & 1072 \\
\hline
\end{tabular}

Note. Statistics presented above by Carey and McDevitt were taken from "Revision of the Infant Temperament Questionnaire,” by W. B. Carey and S. C. McDevitt, 1978, Pediatrics, 61, p. 735739. Test-retest reliabilities were not conducted on the NICHD SECC sample because data on the RITQ were only available at one time point (i.e., 6 months).

${ }^{\mathrm{a}}$ Correlations were computed from maternal ratings of infants between 4 and 8 months of age, with a mean retest interval of 25.1 days. ${ }^{b}$ Correlations among items in each category obtained from infants between 4 and 8 months of age. 
Table 3

Means and Standard Deviations for Revised Infant Temperament Questionnaire Subscales Obtained by the NICHD SECC

\begin{tabular}{|c|c|c|c|c|c|}
\hline & Activity & Approach & Adaptability & Intensity & Mood \\
\hline \multicolumn{6}{|c|}{ Carey and } \\
\hline & (high) & (withdr.) & (non-ada.) & (intense) & (negative) \\
\hline$+1 \mathrm{SD}$ & 4.96 & 3.05 & 2.61 & 4.13 & 3.49 \\
\hline Mean & 4.40 & 2.27 & 2.02 & 3.42 & 2.81 \\
\hline \multirow[t]{2}{*}{$-1 \mathrm{SD}$} & 3.84 & 1.49 & 1.43 & 2.71 & 2.13 \\
\hline & (low) & (app.) & (adapt.) & (mild) & (positive) \\
\hline \multicolumn{6}{|c|}{ NICHD SECC } \\
\hline & (high) & (withdr.) & (non-ada.) & (intense) & (negative) \\
\hline$+1 \mathrm{SD}$ & 4.94 & 3.10 & 2.87 & 4.25 & 3.54 \\
\hline Mean & 4.39 & 2.40 & 2.25 & 3.61 & 2.88 \\
\hline \multirow[t]{2}{*}{$-1 \mathrm{SD}$} & 3.84 & 1.70 & 1.63 & 2.97 & 2.22 \\
\hline & (low) & (app.) & (adapt.) & (mild) & (positive) \\
\hline
\end{tabular}

aFrom “Revised Infant Temperament Questionnaire: Profile Sheet for 4-11-Month-Old Infants," by W. B. Carey and S. C. McDevitt, 1977-1995.

${ }^{\mathrm{b}} N=1072$ 
Table 4

Reliability of Child Behavior Checklist/2-3 Subscales

\begin{tabular}{|c|c|c|c|c|c|}
\hline \multirow[b]{2}{*}{ Subscale } & \multirow[b]{2}{*}{ Items } & \multicolumn{2}{|c|}{ Achenbach } & \multicolumn{2}{|c|}{ NICHD SECC } \\
\hline & & $\begin{array}{l}\text { Test-retest } \\
\text { reliability }^{\mathrm{a}}\end{array}$ & $\begin{array}{c}\text { Internal } \\
\text { consistency }^{\mathrm{b}}\end{array}$ & $\begin{array}{l}\text { Test-retest } \\
\text { reliability }^{\mathrm{c}}\end{array}$ & $\begin{array}{c}\text { Internal } \\
\text { consistency }^{\mathrm{d}}\end{array}$ \\
\hline Internalizing & $\begin{array}{c}\text { Anxious/Depressed } \\
\text { Withdrawn }\end{array}$ & .87 & .88 & .66 & .82 \\
\hline Externalizing & $\begin{array}{l}\text { Aggressive } \\
\text { Destructive }\end{array}$ & .84 & .93 & .72 & .88 \\
\hline $\begin{array}{l}\text { Anxious/ } \\
\text { Depressed }\end{array}$ & & .77 & .78 & .60 & .72 \\
\hline Withdrawn & & .84 & .84 & .62 & .72 \\
\hline $\begin{array}{l}\text { Sleep } \\
\text { Problems }\end{array}$ & & .93 & .83 & .60 & .75 \\
\hline $\begin{array}{l}\text { Somatic } \\
\text { Problems }\end{array}$ & & .86 & .65 & .58 & .57 \\
\hline $\begin{array}{l}\text { Aggressive } \\
\text { Behavior }\end{array}$ & & .86 & .92 & .68 & .85 \\
\hline $\begin{array}{l}\text { Destructive } \\
\text { Behavior }\end{array}$ & & .72 & .83 & .68 & .72 \\
\hline $\begin{array}{l}\text { Total } \\
\text { Problem } \\
\text { Behavior }\end{array}$ & & .91 & .96 & .74 & .93 \\
\hline
\end{tabular}

Note. From Manual for the Child Behavior Checklist/2-3 and 1992 profile, by T. M. Achenbach, 1992, p. 44-47, 189.

${ }^{\mathrm{a}}$ Correlations were computed from maternal ratings of 61 nonreferred 2- and 3-year-olds, with a mean retest interval of 7.7 days. ${ }^{b}$ Cronbach's alpha was obtained on a matched referred and nonreferred sample of 3212 - and 3-year-old-children. ${ }^{\mathrm{c}}$ Correlations were computed from maternal ratings of 1,072 children, with a retest interval of one year. ${ }^{\mathrm{d}}$ Cronbach's alpha was obtained for 1,072 children at 24 months of age. 
Table 5

Child Behavior Checklist/2-3 Items Relevant to Inhibition in Early Childhood

\begin{tabular}{cl}
\hline Item & Loading on syndrome scale \\
\hline
\end{tabular}

3. Afraid to try new things

4. Avoids looking in the eye

Withdrawn

10. Clings to adults or too dependent

Anxious/Depressed

21. Disturbed by any change in routine

22. Doesn't want to sleep alone

Sleep Problems

28. Doesn't want to go out of home

32. Fears certain animals, situations, or places

37. Gets too upset when separated from parents

Anxious/Depressed

47. Nervous, highstrung, or tense

Anxious/Depressed

68. Self-conscious or easily embarrassed

Anxious/Depressed

73. Shy or timid

Anxious/Depressed

87. Too fearful or anxious

Anxious/Depressed

92. Upset by new people or situations

98. Withdrawn, doesn't get involved

Withdrawn

Note. From Manual for the Child Behavior Checklist/2-3 and 1992 profile, by T. M. Achenbach, 1992, p. 4-5, 187-188. 
Table 6

Stability (Test-Retest Reliability) for Maternal and Child Behaviors

Ages (in Months)

\begin{tabular}{|c|c|c|c|c|c|c|}
\hline & 6 to 15 & 6 to 24 & 6 to 36 & 15 to 24 & 15 to 36 & 24 to 36 \\
\hline HOME Total Score & $.55^{* *}$ & & $.44^{* *}$ & & $.56^{* *}$ & \\
\hline Maternal Sensitivity & $.37 * *$ & $.29 * *$ & $.39 * *$ & $.37 * *$ & $.38 * *$ & $.45^{* *}$ \\
\hline Inhibition & & & & & & $.57 * *$ \\
\hline Activity & & .04 & & & & \\
\hline Positivity & $.10 * *$ & $.07 *$ & $.08 *$ & $.12 * *$ & .06 & $.24 * *$ \\
\hline Negativity & $.10 * *$ & $.11^{* *}$ & $.11 * *$ & $.10 * *$ & $.14 * *$ & $.25 * *$ \\
\hline
\end{tabular}

Note. $N=1072$. Stability was assessed with Pearson's product-moment $(r)$ correlations.

${ }^{*} p<.05 . * * p<.01$. 
Table 7

Mean Scores on Temperament Dimensions for Infants in Each Temperament Category

\begin{tabular}{lccccc}
\hline \multirow{2}{*}{ Dimension } & \multicolumn{5}{c}{ Category } \\
\cline { 3 - 6 } Activity & Behavior $^{\mathrm{a}}$ & Easy & Difficult & $\begin{array}{c}\text { Slow-to-warm- } \\
\text { up }\end{array}$ & Intermediate \\
Approach & Active & 4.30 & 4.66 & 3.97 & 4.51 \\
Adaptability & $\begin{array}{c}\text { Withdrawing } \\
\text { Non- }\end{array}$ & 1.98 & 3.33 & 3.04 & 2.57 \\
Intensity & $\begin{array}{c}\text { Intense } \\
\text { Mood }\end{array}$ & 3.35 & 3.09 & 2.90 & 2.40 \\
$n$ & Negative & 2.51 & 4.17 & 3.29 & 3.89 \\
\hline
\end{tabular}

Note. Ratings were made using the RITQ.

${ }^{\mathrm{a}}$ Higher numbers denote higher levels of the specified behavior. 
Table 8

Number of Participants with Missing Data for Each Variable

\begin{tabular}{|c|c|c|c|c|}
\hline \multirow[b]{2}{*}{ Variable } & \multicolumn{4}{|c|}{ Age (in Months) } \\
\hline & 6 & 15 & 24 & 36 \\
\hline Activity & 4 & & 104 & \\
\hline Positive Mood & 4 & 48 & 104 & 115 \\
\hline Negative Mood & 4 & 48 & 104 & 115 \\
\hline Sensitivity & 4 & 48 & 104 & 115 \\
\hline HOME Total & 1 & 51 & & 96 \\
\hline Quality of Interaction & 3 & & & \\
\hline Inhibition & & & 91 & 106 \\
\hline
\end{tabular}

Note. $N=1,072$ participants for whom temperament data were available. 
Table 9

Mean Scores on Dependent Variables by Temperament Category and Age in Months

Temperament

\begin{tabular}{|c|c|c|c|c|c|c|}
\hline \multirow[b]{2}{*}{ DV } & \multicolumn{6}{|c|}{ Slow-to-Warm-Up } \\
\hline & 6 & 15 & 24 & $36^{\mathrm{a}}$ & $36^{\mathrm{b}}$ & $\operatorname{Avg}^{c}$ \\
\hline Inhibition & & & $\begin{array}{c}6.45 \\
(3.93)\end{array}$ & $\begin{array}{c}5.98 \\
(3.74)\end{array}$ & & $\begin{array}{c}6.21 \\
(3.44)\end{array}$ \\
\hline Sensitivity & $\begin{array}{c}9.07 \\
(1.50)\end{array}$ & $\begin{array}{c}9.25 \\
(1.67)\end{array}$ & $\begin{array}{c}9.09 \\
(1.74)\end{array}$ & $\begin{array}{l}16.62 \\
(2.50)\end{array}$ & $\begin{array}{c}9.81 \\
(1.25)\end{array}$ & $\begin{array}{c}9.30 \\
(1.12)\end{array}$ \\
\hline $\begin{array}{l}\text { Stimulation/ } \\
\text { Support }\end{array}$ & $\begin{array}{l}36.17 \\
(4.92)\end{array}$ & $\begin{array}{l}36.45 \\
(4.47)\end{array}$ & & $\begin{array}{l}41.08 \\
(6.00)\end{array}$ & $\begin{array}{l}33.61 \\
(4.91)\end{array}$ & $\begin{array}{l}35.41 \\
(3.77)\end{array}$ \\
\hline Activity & $\begin{array}{l}2.29 \\
(.46)\end{array}$ & & $\begin{array}{l}2.69 \\
(.54)\end{array}$ & & & $\begin{array}{l}2.49 \\
(.35)\end{array}$ \\
\hline $\begin{array}{l}\text { Positive } \\
\text { mood }\end{array}$ & $\begin{array}{l}2.49 \\
(.54)\end{array}$ & $\begin{array}{l}2.54 \\
(.69)\end{array}$ & $\begin{array}{l}2.72 \\
(.63)\end{array}$ & $\begin{array}{c}4.74 \\
(1.19)\end{array}$ & $\begin{array}{l}2.87 \\
(.60)\end{array}$ & $\begin{array}{l}2.66 \\
(.37)\end{array}$ \\
\hline $\begin{array}{l}\text { Negative } \\
\text { mood }\end{array}$ & $\begin{array}{l}1.42 \\
(.70)\end{array}$ & $\begin{array}{l}1.27 \\
(.63)\end{array}$ & $\begin{array}{l}1.52 \\
(.75)\end{array}$ & $\begin{array}{c}1.87 \\
(1.17)\end{array}$ & $\begin{array}{l}1.43 \\
(.59)\end{array}$ & $\begin{array}{l}1.41 \\
(.39)\end{array}$ \\
\hline
\end{tabular}

Note. Total $N=1072 . n=59,492,89$, and 435 for slow-to-warm-up, easy, difficult, and intermediate temperaments, respectively. Standard deviations are in parentheses. For inhibition, the scale ranged from 0 to 14 . For sensitivity, the scale ranged from 3 to 12 at $6,15,24$, and 36 (transformed) months and from 3 to 21 at 36 months (untransformed). For stimulation/support, the scale ranged from 0 to 45 at 6,15 , and 36 (transformed) months and from 0 to 55 at 36 months (untransformed). For activity, positive mood, and negative mood, the scale ranged from 1 to 4 at 6, 15, 24, and 36 (transformed) months and from 1 to 7 at 36 (untransformed) months. ${ }^{\mathrm{a}}$ Based on 36-month untransformed scores. ${ }^{\mathrm{b}}$ Based on 36-month transformed scores. ${ }^{\mathrm{c}}$ Based on average of 6, 15, 24 and 36-month transformed scores. 
Table 9

Mean Scores on Dependent Variables by Temperament Category and Age in Months

\begin{tabular}{|c|c|c|c|c|c|c|}
\hline \multirow[b]{3}{*}{ DV } & \multicolumn{6}{|c|}{ Temperament } \\
\hline & \multicolumn{6}{|c|}{ Easy } \\
\hline & 6 & 15 & 24 & $36^{\mathrm{a}}$ & $36^{\mathrm{b}}$ & $A v g^{c}$ \\
\hline Inhibition & & & $\begin{array}{c}4.62 \\
(3.04)\end{array}$ & $\begin{array}{c}5.25 \\
(3.07)\end{array}$ & & $\begin{array}{c}4.94 \\
(2.70)\end{array}$ \\
\hline Sensitivity & $\begin{array}{c}9.46 \\
(1.58)\end{array}$ & $\begin{array}{c}9.65 \\
(1.46)\end{array}$ & $\begin{array}{c}9.61 \\
(1.51)\end{array}$ & $\begin{array}{l}17.69 \\
(2.19)\end{array}$ & $\begin{array}{l}10.33 \\
(1.09)\end{array}$ & $\begin{array}{l}9.76 \\
(.99)\end{array}$ \\
\hline $\begin{array}{l}\text { Stimulation/ } \\
\text { Support }\end{array}$ & $\begin{array}{l}37.50 \\
(3.80)\end{array}$ & $\begin{array}{l}38.11 \\
(3.47)\end{array}$ & & $\begin{array}{l}42.56 \\
(6.02)\end{array}$ & $\begin{array}{l}34.82 \\
(4.92)\end{array}$ & $\begin{array}{l}36.81 \\
(3.20)\end{array}$ \\
\hline Activity & $\begin{array}{l}2.46 \\
(.56)\end{array}$ & & $\begin{array}{l}2.75 \\
(.60)\end{array}$ & & & $\begin{array}{l}2.60 \\
(.42)\end{array}$ \\
\hline $\begin{array}{l}\text { Positive } \\
\text { mood }\end{array}$ & $\begin{array}{l}2.51 \\
(.62)\end{array}$ & $\begin{array}{l}2.49 \\
(.65)\end{array}$ & $\begin{array}{l}2.80 \\
(.65)\end{array}$ & $\begin{array}{l}5.03 \\
(.96)\end{array}$ & $\begin{array}{l}3.01 \\
(.48)\end{array}$ & $\begin{array}{l}2.70 \\
(.35)\end{array}$ \\
\hline $\begin{array}{l}\text { Negative } \\
\text { mood }\end{array}$ & $\begin{array}{l}1.39 \\
(.66)\end{array}$ & $\begin{array}{l}1.26 \\
(.55)\end{array}$ & $\begin{array}{l}1.44 \\
(.66)\end{array}$ & $\begin{array}{c}2.04 \\
(1.18)\end{array}$ & $\begin{array}{l}1.34 \\
(.54)\end{array}$ & $\begin{array}{l}1.36 \\
(.36)\end{array}$ \\
\hline
\end{tabular}


Table 9

Mean Scores on Dependent Variables by Temperament Category and Age in Months

\begin{tabular}{|c|c|c|c|c|c|c|}
\hline \multirow[b]{3}{*}{ DV } & \multicolumn{6}{|c|}{ Temperament } \\
\hline & \multicolumn{6}{|c|}{ Difficult } \\
\hline & 6 & 15 & 24 & $36^{\mathrm{a}}$ & $36^{\mathrm{b}}$ & $\operatorname{Avg}^{c}$ \\
\hline Inhibition & & & $\begin{array}{c}7.29 \\
(3.35)\end{array}$ & $\begin{array}{c}7.71 \\
(3.20)\end{array}$ & & $\begin{array}{c}7.50 \\
(2.74)\end{array}$ \\
\hline Sensitivity & $\begin{array}{c}8.54 \\
(1.94)\end{array}$ & $\begin{array}{c}8.85 \\
(1.74)\end{array}$ & $\begin{array}{c}8.93 \\
(1.64)\end{array}$ & $\begin{array}{l}16.24 \\
(2.78)\end{array}$ & $\begin{array}{c}9.62 \\
(1.39)\end{array}$ & $\begin{array}{c}8.99 \\
(1.24)\end{array}$ \\
\hline $\begin{array}{l}\text { Stimulation/ } \\
\text { Support }\end{array}$ & $\begin{array}{l}34.30 \\
(4.98)\end{array}$ & $\begin{array}{l}35.90 \\
(5.13)\end{array}$ & & $\begin{array}{l}37.43 \\
(8.61)\end{array}$ & $\begin{array}{l}30.63 \\
(7.04)\end{array}$ & $\begin{array}{l}33.61 \\
(4.68)\end{array}$ \\
\hline Activity & $\begin{array}{l}2.56 \\
(.56)\end{array}$ & & $\begin{array}{l}2.79 \\
(.59)\end{array}$ & & & $\begin{array}{l}2.67 \\
(.36)\end{array}$ \\
\hline $\begin{array}{l}\text { Positive } \\
\text { mood }\end{array}$ & $\begin{array}{l}2.46 \\
(.62)\end{array}$ & $\begin{array}{l}2.41 \\
(.55)\end{array}$ & $\begin{array}{l}2.75 \\
(.69)\end{array}$ & $\begin{array}{c}4.74 \\
(1.10)\end{array}$ & $\begin{array}{l}2.87 \\
(.55)\end{array}$ & $\begin{array}{l}2.62 \\
(.36)\end{array}$ \\
\hline $\begin{array}{l}\text { Negative } \\
\text { mood }\end{array}$ & $\begin{array}{l}1.49 \\
(.71)\end{array}$ & $\begin{array}{l}1.27 \\
(.55)\end{array}$ & $\begin{array}{l}1.52 \\
(.71)\end{array}$ & $\begin{array}{c}1.67 \\
(1.09)\end{array}$ & $\begin{array}{l}1.52 \\
(.59)\end{array}$ & $\begin{array}{l}1.45 \\
(.37)\end{array}$ \\
\hline
\end{tabular}


Table 9

Mean Scores on Dependent Variables by Temperament Category and Age in Months

Temperament

\begin{tabular}{|c|c|c|c|c|c|c|}
\hline \multirow[b]{2}{*}{ DV } & \multicolumn{6}{|c|}{ Intermediate } \\
\hline & 6 & 15 & 24 & $36^{\mathrm{a}}$ & $36^{\mathrm{b}}$ & $\operatorname{Avg}^{c}$ \\
\hline Inhibition & & & $\begin{array}{c}5.80 \\
(3.29)\end{array}$ & $\begin{array}{c}6.03 \\
(3.39)\end{array}$ & & $\begin{array}{c}5.92 \\
(2.95)\end{array}$ \\
\hline Sensitivity & $\begin{array}{c}9.10 \\
(1.88)\end{array}$ & $\begin{array}{c}9.29 \\
(1.62)\end{array}$ & $\begin{array}{c}9.35 \\
(1.67)\end{array}$ & $\begin{array}{l}17.07 \\
(2.57)\end{array}$ & $\begin{array}{l}10.33 \\
(1.28)\end{array}$ & $\begin{array}{c}9.44 \\
(1.18)\end{array}$ \\
\hline $\begin{array}{l}\text { Stimulation/ } \\
\text { Support }\end{array}$ & $\begin{array}{l}36.25 \\
(4.79)\end{array}$ & $\begin{array}{l}37.14 \\
(4.53)\end{array}$ & & $\begin{array}{l}41.53 \\
(6.94)\end{array}$ & $\begin{array}{l}33.98 \\
(5.67)\end{array}$ & $\begin{array}{l}35.79 \\
(4.21)\end{array}$ \\
\hline Activity & $\begin{array}{l}2.44 \\
(.57)\end{array}$ & & $\begin{array}{l}2.73 \\
(.58)\end{array}$ & & & $\begin{array}{l}2.58 \\
(.42)\end{array}$ \\
\hline $\begin{array}{l}\text { Positive } \\
\text { mood }\end{array}$ & $\begin{array}{l}2.50 \\
(.65)\end{array}$ & $\begin{array}{l}2.48 \\
(.61)\end{array}$ & $\begin{array}{l}2.78 \\
(.64)\end{array}$ & $\begin{array}{l}5.03 \\
(.96)\end{array}$ & $\begin{array}{l}2.97 \\
(.49)\end{array}$ & $\begin{array}{l}2.68 \\
(.34)\end{array}$ \\
\hline $\begin{array}{l}\text { Negative } \\
\text { mood }\end{array}$ & $\begin{array}{l}1.41 \\
(.71)\end{array}$ & $\begin{array}{l}1.26 \\
(.54)\end{array}$ & $\begin{array}{l}1.40 \\
(.66)\end{array}$ & $\begin{array}{l}1.64 \\
(.95)\end{array}$ & $\begin{array}{l}1.32 \\
(.48)\end{array}$ & $\begin{array}{l}1.35 \\
(.35)\end{array}$ \\
\hline
\end{tabular}


Table 10

Summary of Regression Analyses for Variables Predicting 24- and 36-month Inhibition

\begin{tabular}{|c|c|c|c|c|c|c|}
\hline \multirow[b]{2}{*}{ Variable } & \multicolumn{3}{|c|}{24 months } & \multicolumn{3}{|c|}{36 months } \\
\hline & $B$ & $S E B$ & B & $B$ & SE B & $\beta$ \\
\hline \multicolumn{7}{|l|}{ Linear } \\
\hline STWU & $1.09 *$ & .44 & $.08 *$ & .18 & .44 & .01 \\
\hline \multicolumn{7}{|l|}{ Multiple } \\
\hline Activity & -.10 & .21 & -.02 & -.11 & .21 & -.02 \\
\hline Approach & $.90 * *$ & .20 & $.19 * *$ & $.59 * *$ & .20 & $.12 * *$ \\
\hline Adaptability & .44 & .23 & .08 & .43 & .23 & .08 \\
\hline Intensity & .11 & .17 & .02 & .03 & .17 & .01 \\
\hline Mood & $.40^{*}$ & .18 & $.08 *$ & $.50 * *$ & .19 & $.10 * *$ \\
\hline
\end{tabular}

Note. $N=1072$. Slow-to-warm-up temperament was entered in a linear regression predicting inhibition at each age. $R^{2}=.01$ and Adjusted $\mathrm{R}^{2}=.01$ at 24 months; $R^{2}=.00$ and Adjusted $R^{2}$ $=.00$ at 36 months. The subscales were entered in a multiple regression with standard entry predicting inhibition at each age. $R^{2}=.09$ and Adjusted $R^{2}=.09$ at 24 months; $R^{2}=.07$ and Adjusted $R^{2}=.06$ at 36 months.

$* p<.05 . * * p<.01$. 
Table 11

Analysis of Variance for Temperament and Mood at 6, 15, 24, and 36 Months of Age

\begin{tabular}{lcccc}
\hline Source & $d f$ & $F$ & $\eta$ & $p$ \\
\hline & Between-subjects & \\
$\begin{array}{l}\text { Temperament } \\
(T)\end{array}$ & 3 & 1.15 & .00 & .33 \\
$\begin{array}{l}S \text { within-group } \\
\text { error }\end{array}$ & 1068 & $(.02)$ & & \\
\hline
\end{tabular}

Within-subjects

$\begin{array}{lcccc}\text { Age (A) } & 2.88 & 61.81^{* *} & .06 & .00 \\ \text { Mood (M) } & 1 & 2912.68^{* *} & .73 & .00 \\ \text { A x T } & 8.65 & 0.48 & .00 & .89 \\ \text { A x M } & 2.84 & 11.36^{* *} & .01 & .00 \\ \text { M x T } & 3 & 3.15^{*} & .01 & .02 \\ \begin{array}{l}\text { A x M x T } \\ \begin{array}{l}\text { A x } S \text { within- } \\ \text { group error }\end{array}\end{array} & 3079.79 & (.01) & .00 & .51 \\ \begin{array}{l}\text { M x } S \text { within- } \\ \text { group error }\end{array} & 1068 & 0.92 & & \\ \begin{array}{l}\text { A x M x } S \\ \text { within-group } \\ \text { error }\end{array} & 3033.06 & (.02) & \end{array}$

Note. Mean square errors are in parentheses. $S=$ subjects.

${ }^{*} p<.05 . * *<<.01$ 
Table 12

Mean Inhibition Scores for Groups Based on Sensitivity, Stimulation/Support, and Quality of Interaction.

\begin{tabular}{|c|c|c|c|c|c|c|c|c|c|}
\hline \multirow[b]{2}{*}{ DV } & \multicolumn{3}{|c|}{ Low } & \multicolumn{3}{|c|}{ Average } & \multicolumn{3}{|c|}{ High } \\
\hline & $\begin{array}{c}24 \\
\text { months }\end{array}$ & $\begin{array}{c}36 \\
\text { months }\end{array}$ & $n$ & $\begin{array}{c}24 \\
\text { months }\end{array}$ & $\begin{array}{c}36 \\
\text { months }\end{array}$ & $n$ & $\begin{array}{c}24 \\
\text { months }\end{array}$ & $\begin{array}{c}36 \\
\text { months }\end{array}$ & $n$ \\
\hline Sensitivity & $\begin{array}{c}7.42 \\
(4.52)\end{array}$ & $\begin{array}{c}6.53 \\
(4.41)\end{array}$ & 16 & $\begin{array}{c}6.09 \\
(3.83)\end{array}$ & $\begin{array}{c}5.71 \\
(3.76)\end{array}$ & 23 & $\begin{array}{c}6.07 \\
(3.60)\end{array}$ & $\begin{array}{c}5.85 \\
(3.27)\end{array}$ & 20 \\
\hline Stim/Support & $\begin{array}{c}7.16 \\
(3.49)\end{array}$ & $\begin{array}{c}6.75 \\
(3.58)\end{array}$ & 19 & $\begin{array}{c}5.89 \\
(3.93)\end{array}$ & $\begin{array}{c}5.98 \\
(3.62)\end{array}$ & 19 & $\begin{array}{c}6.31 \\
(4.38)\end{array}$ & $\begin{array}{c}5.29 \\
(4.03)\end{array}$ & 21 \\
\hline Quality & & & & $\begin{array}{c}5.69 \\
(3.76)\end{array}$ & $\begin{array}{c}6.04 \\
(3.70)\end{array}$ & 37 & $\begin{array}{c}7.72 \\
(3.97)\end{array}$ & $\begin{array}{c}5.87 \\
(3.90)\end{array}$ & 22 \\
\hline
\end{tabular}

Note. Only slow-to-warm-up temperament was included in the analyses. Standard deviations are in parentheses. 


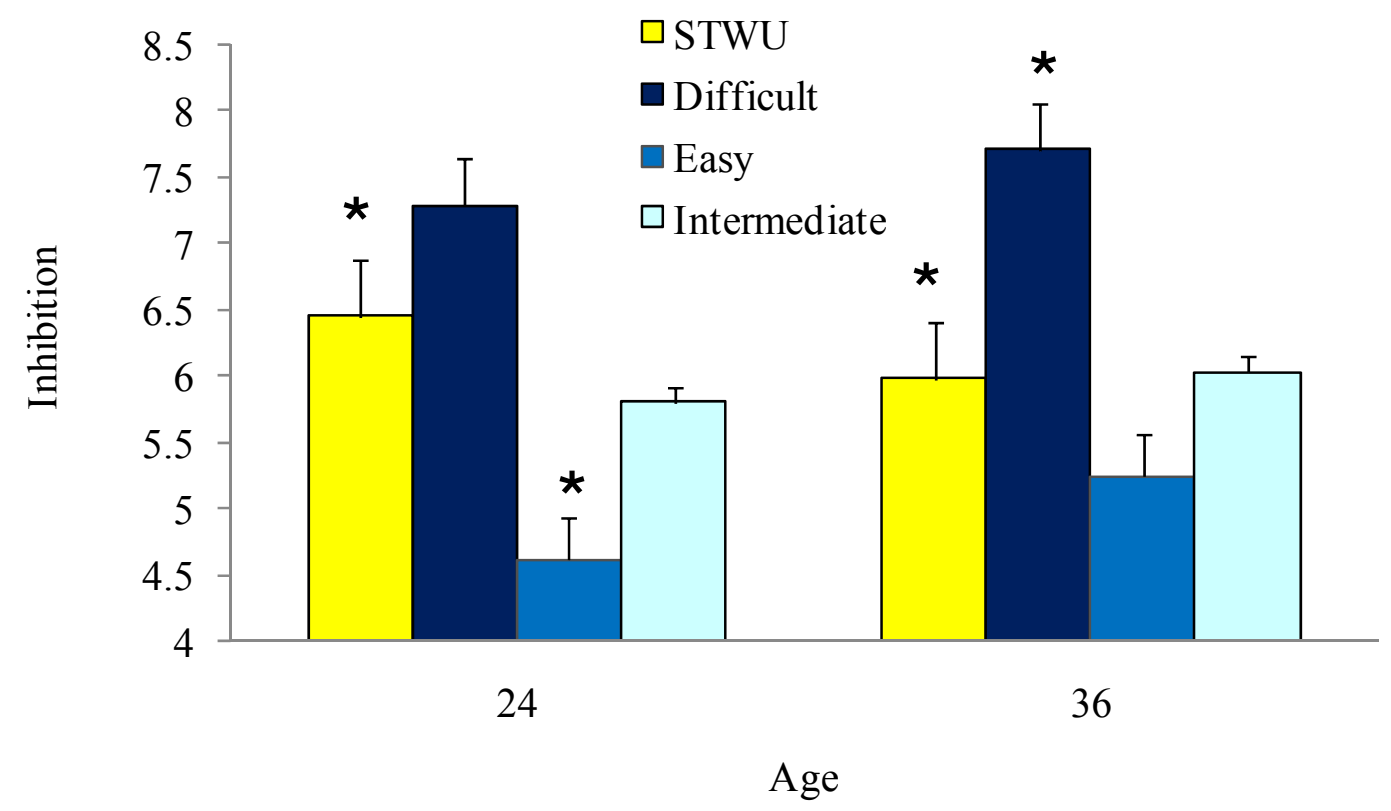




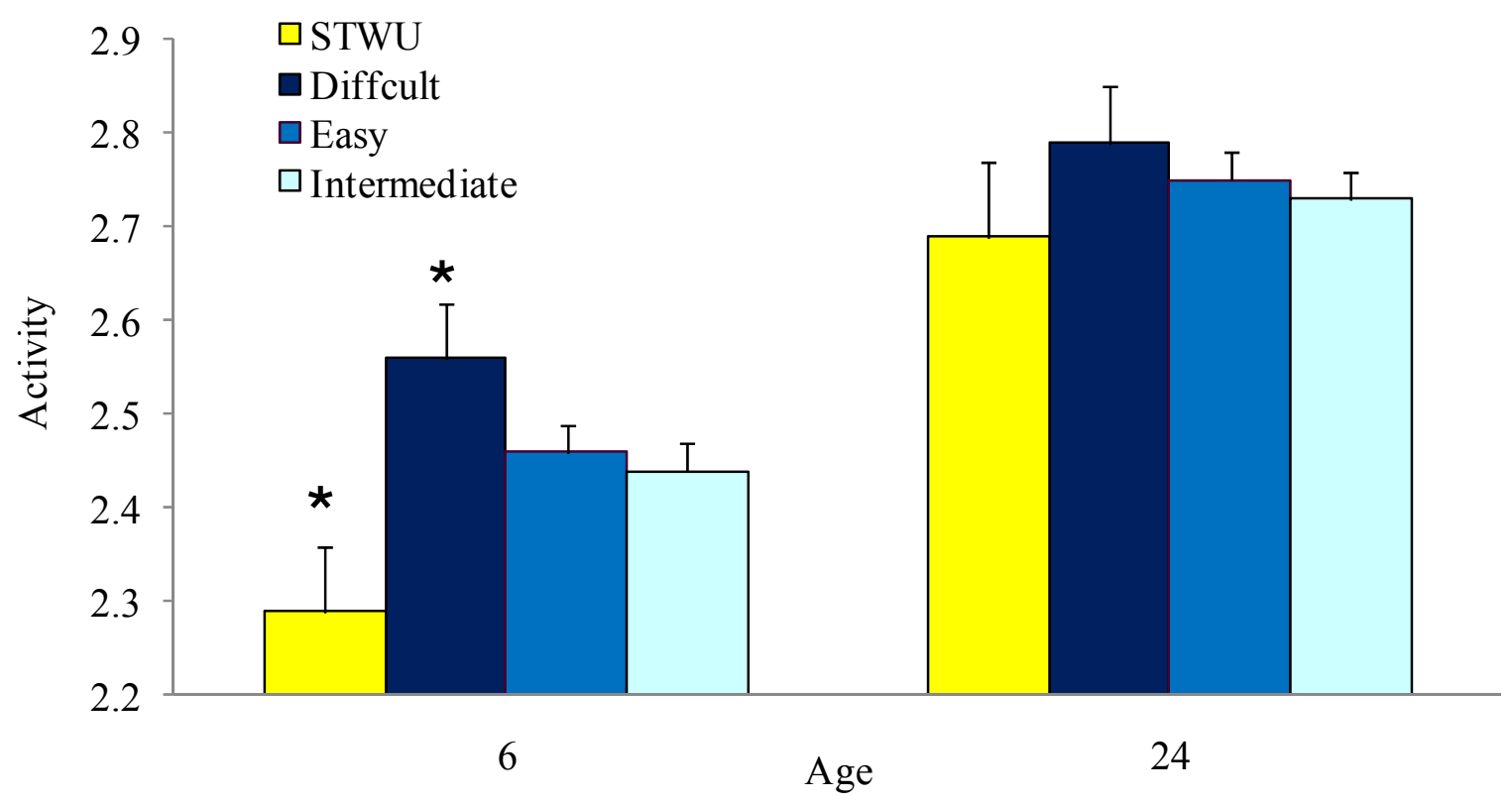




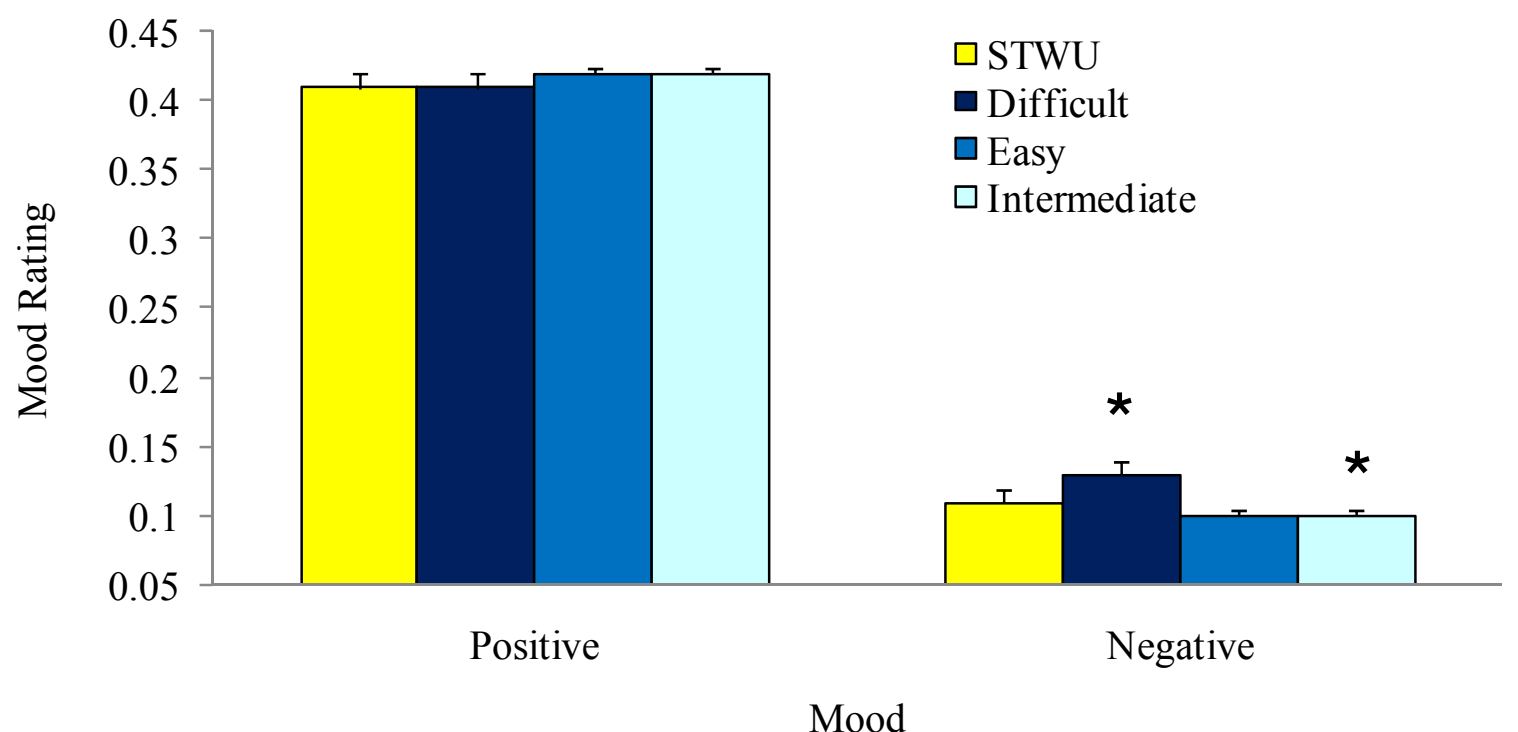


Slow-to-Warm-Up 97

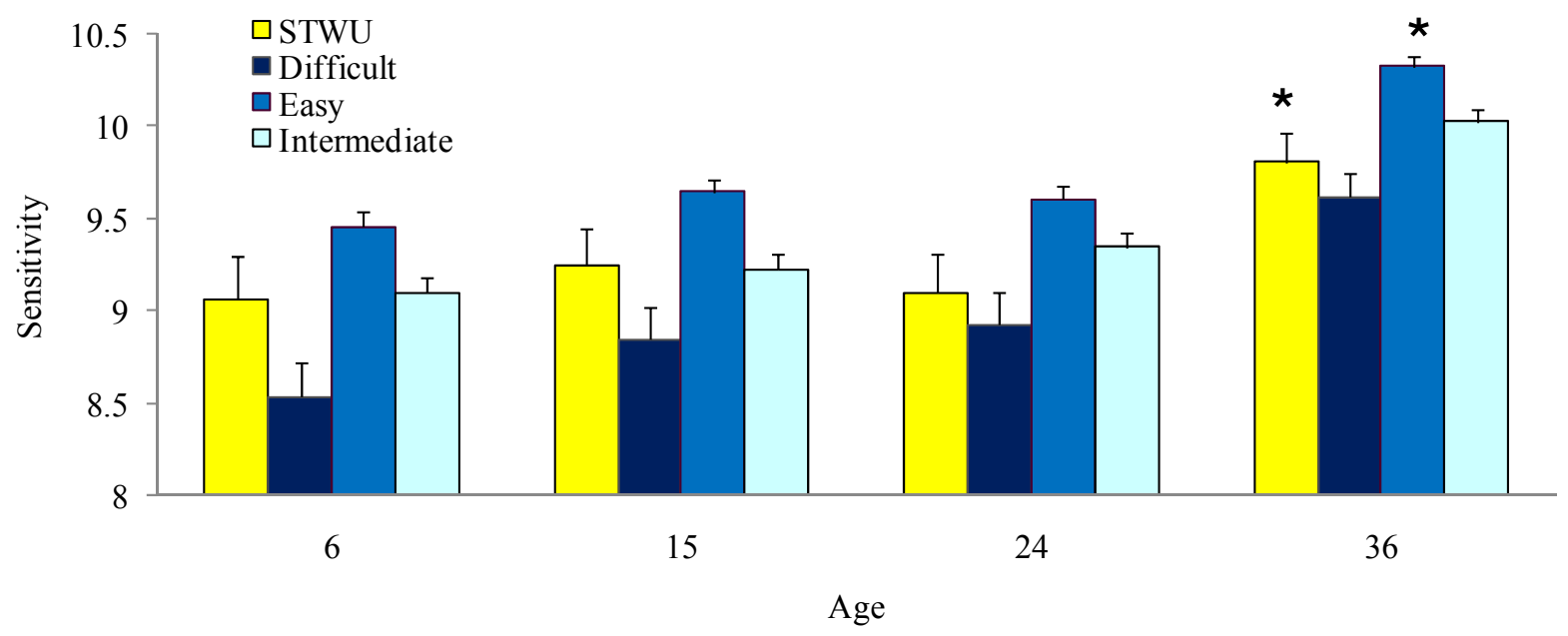




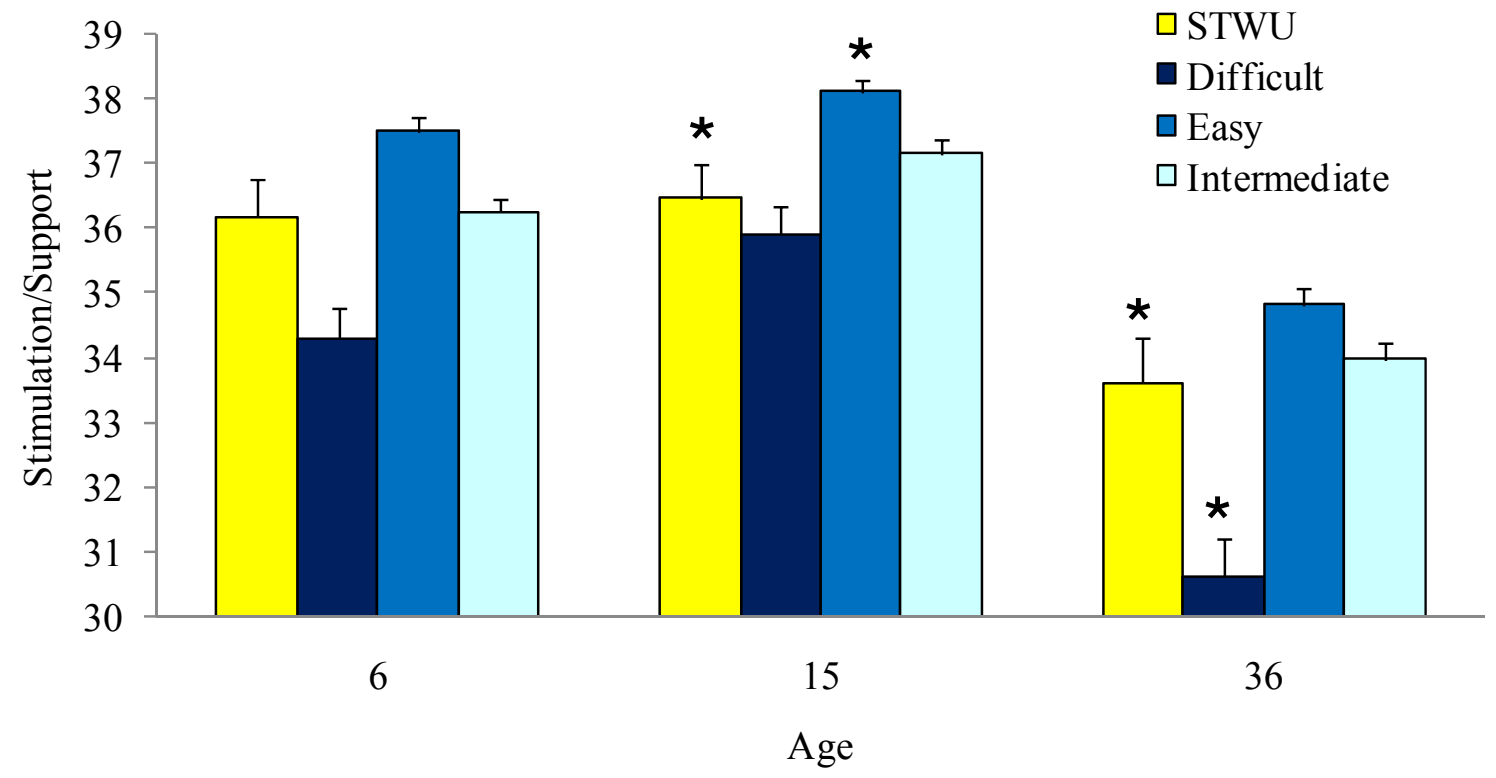




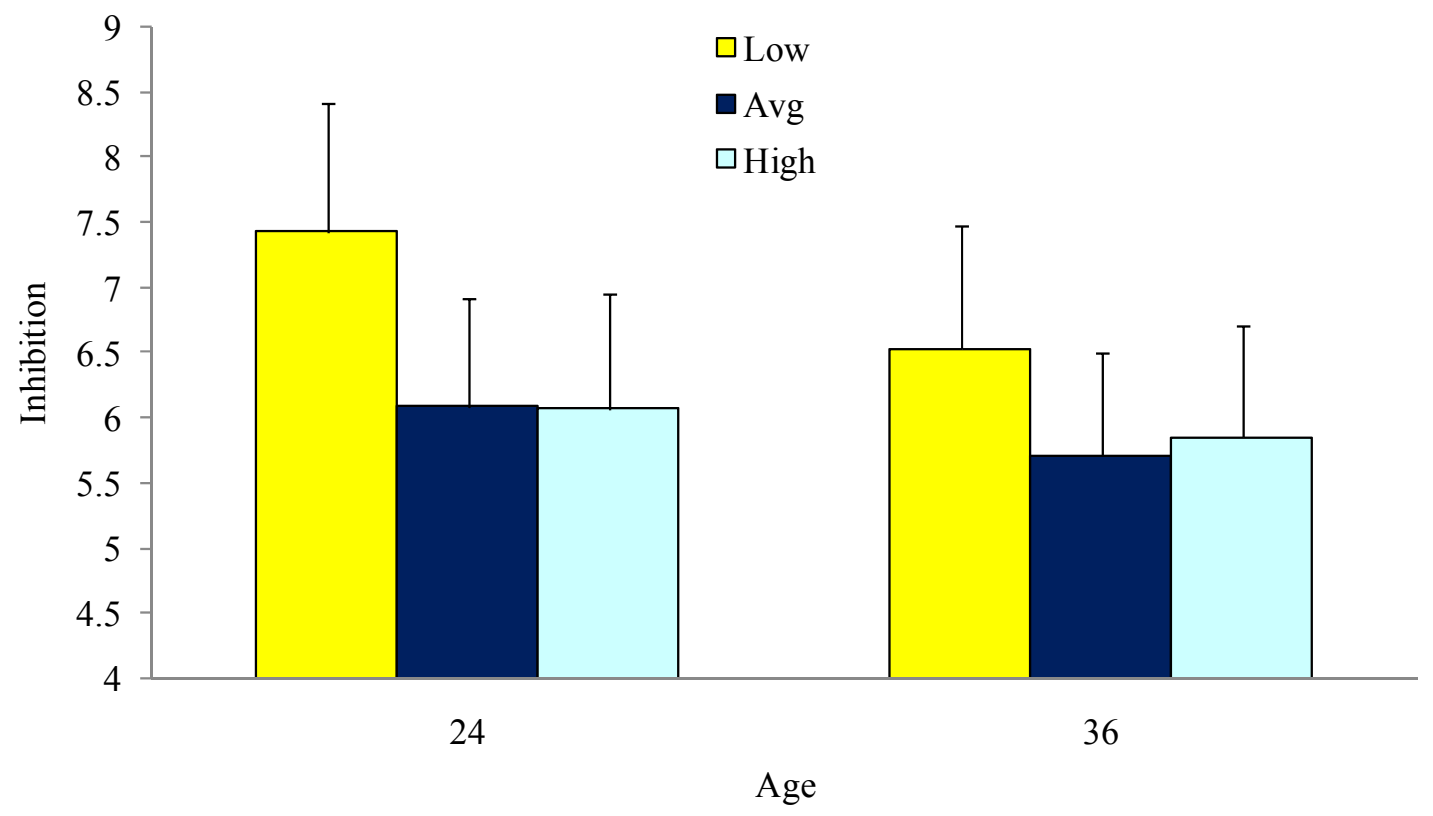




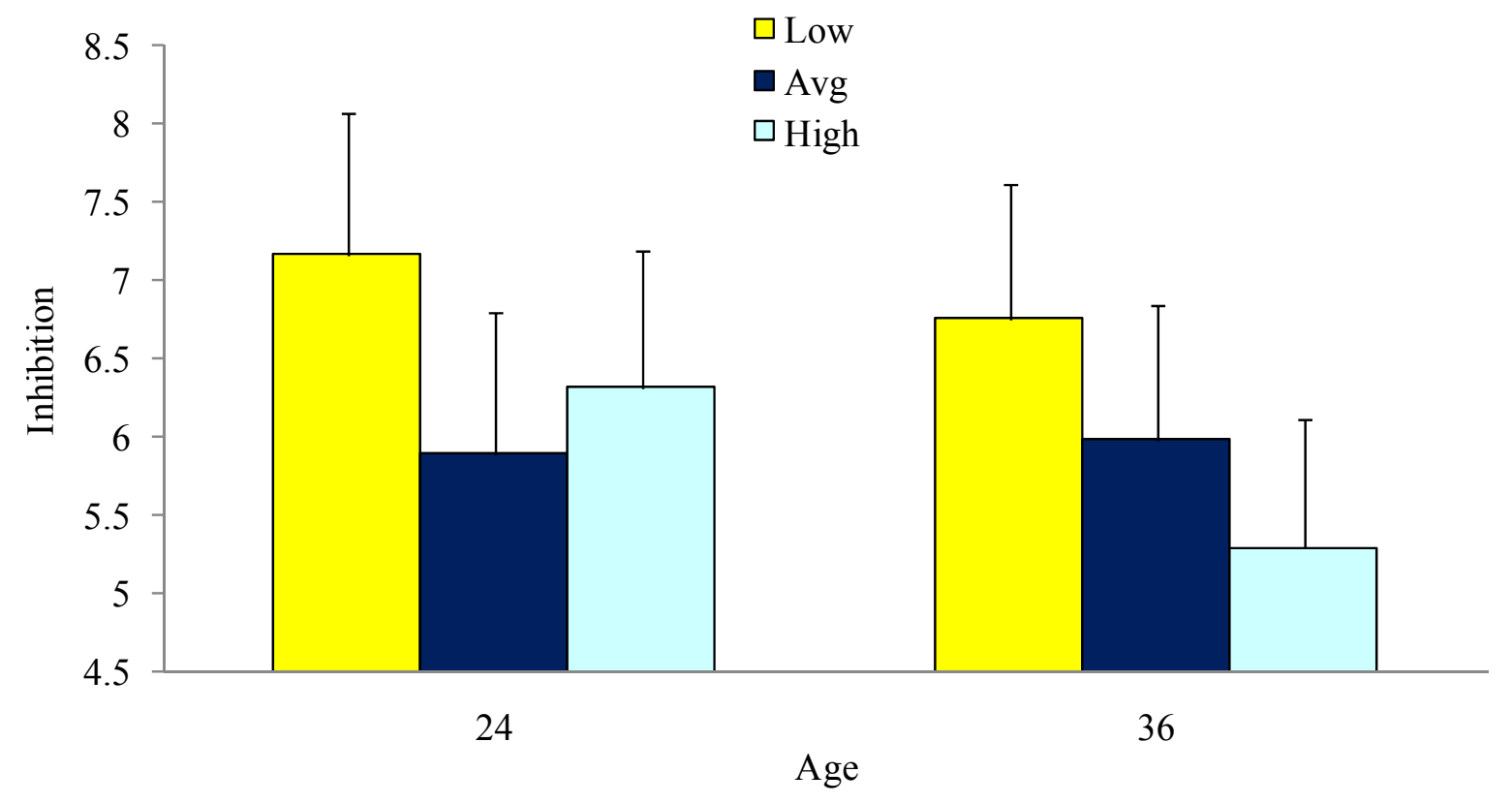




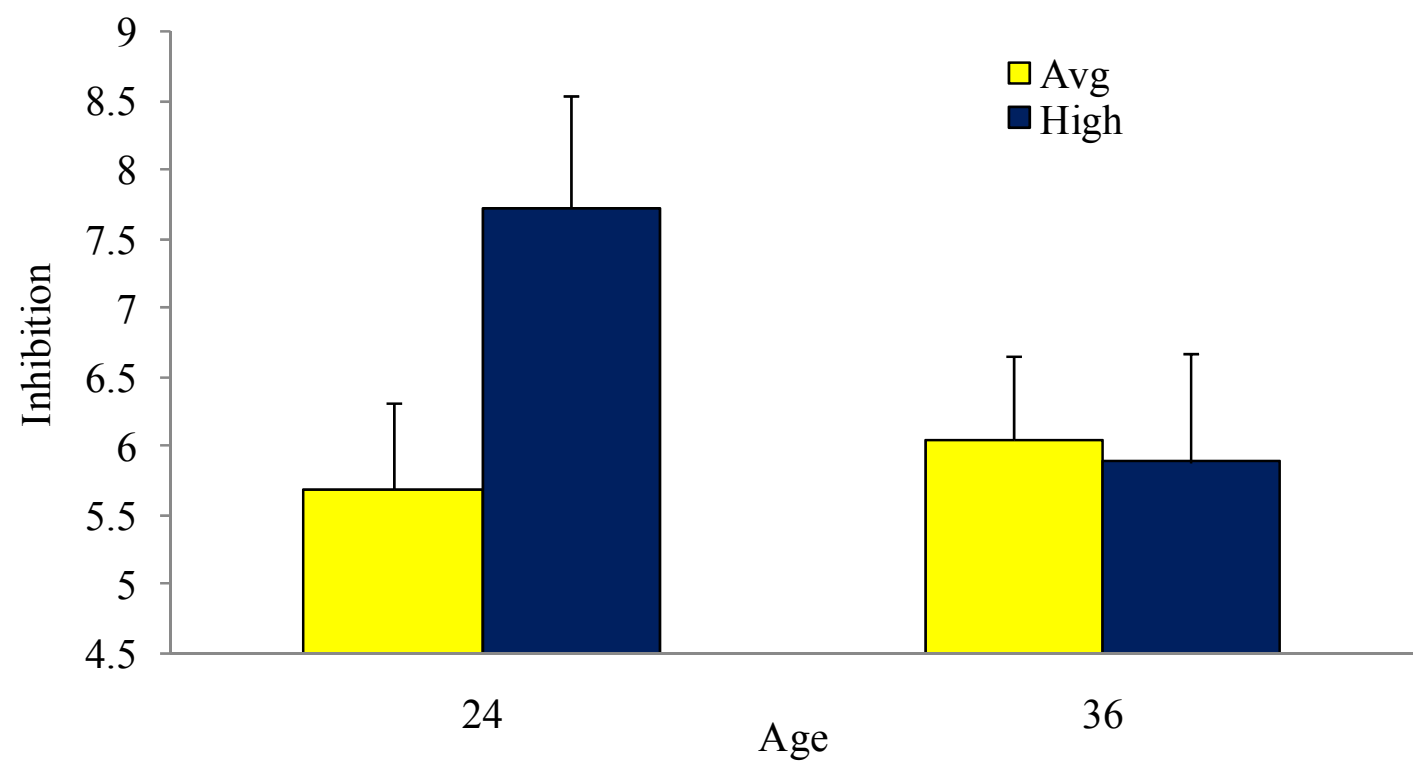

Virginia University Libraries,

ou=Acquisitions Department,

email=John.Hagen@mail.wvu.edu,

$c=$ US

Reason: I am approving this

document

Date: 2008.05 .09 20:19:10-04'00' 